\title{
Configuración de los sistemas socio-ecológicos en zonas metropolitanas. La experiencia en Mérida, Yucatán, México
}

\section{Shaping the socio-ecological systems in Metropolitan Areas. The experience in Merida, Yucatan, Mexico}

Recibido: septiembre 24 de 2019

Karla Juliana Rodríguez-Robayo*

María Elena Méndez-López*

Lilián Juárez-Téllez*

Rosa Martha Peralta-Blanco*

Aceptado: enero 07 de 2020

Resumen

El artículo tiene como objetivo analizar la configuración actual de los sistemas socio-ecológicos en ocho municipios de la zona metropolitana de Mérida (Yucatán, México), a partir de la integración de cartografía regional, entrevistas a actores clave y revisión bibliográfica. Los resultados evidencian que, aunque la zona de estudio ha tenido la histórica tendencia hacia los sectores secundario y terciario, en la actualidad hay dos sistemas socio-ecológicos marcadamente diferenciados, que proveen servicios ecosistémicos relevantes para la ciudad: en el norte caracterizado por la pesca, a picultura y turismo y en el sur por la apicultura y agricultura de temporal. Las recomendaciones destacan la relevancia de conservar y promover la relación sociedad-naturaleza con el fin de consolidar sistemas agroalimentarios sostenibles en la zona metropolitana y conectar las zonas de conservación existentes al norte de la zona de estudio con la selva baja; de tal forma que se constituya un corredor que contenga los servicios ecosistémicos ante el creciente desarrollo económico y urbano de la zona metropolitana.

Palabras clave: sistemas socio-ecológicos, relación sociedad-naturaleza, sector primario, área metropolitana.

\section{Abstract}

The article aims to analyze the current shaping of socio-ecological systems (SES) in eight municipalities in the metropolitan area of Merida (Yucatan, Mexico), based on a methodological proposal that integrates regional cartography, historical evidence, and interviews with key actors. Despite the strong economic history of the region, the results show two SES: In the north, fishing, beekeeping and tourism, and in the south beekeeping and rainfed agriculture. The recommendations highlight the importance of conserving and promoting the relationship between society and its natural resources in order to consolidate sustainable agrifood systems in the metropolitan area and to connect the existing conservation zones at the north of the study area (coast) with the Tropical dry forest.

Keywords: socio-ecological systems, society-nature relationship, metropolitan area.

*Centro de Investigación en Ciencias de Información Geoespacial, México. Correo electrónico: karla.juliana.rodriguez@gmail.com, emendez@centrogeo.edu.mx, ljuarez@centrogeo.edu.mx, rperalta@centrogeo.edu.mx 


\section{Introducción}

El noroeste de Yucatán es una región en donde la cobertura forestal (manglar, selva baja caducifolia y mediana subperennifolia) ocupa parte importante del territorio y ofrece diversos bienes y servicios a la sociedad: aprovisionamiento de alimentos y leña, así como servicios culturales asociados a la belleza escénica, de soporte como la polinización, y de regulación ante eventos climáticos extremos como huracanes y tormentas, entre otros.

Adicionalmente, en esta región se encuentra Mérida; una ciudad en constante crecimiento, la cual, junto con los cinco municipios que conforman su zona metropolitana (Conkal, Kanasín, Progreso, Ucú y Umán), concentra el desarrollo económico del estado (López-Santillán, 2011). Una zona metropolitana (ZM) se refiere a una ciudad central y a un conjunto de unidades político-administrativas (municipios) que se incorporan en un área urbanizada continua que incluye las áreas rurales inmersas (Graizbord y PérezTorres, 2012; Sturzaker y Mell, 2016).

A partir de 1970, la población de la ciudad en Mérida se ha incrementado significativamente, pasando de 250,000 a 900,000 habitantes en 2015 (INEGI, 1970; INEGI, 2015); así, en esta región habita más de la mitad de la población total del estado de Yucatán (Domínguez, 2011).

La riqueza biológica y cultural presente, junto con la dinámica demográfica y económica de la región, orientan nuestra pregunta de investigación: ¿Cómo se configuran actualmente los sistemas socio-ecológicos en la zona metropolitana de Mérida?, y definen el objetivo: analizar la configuración actual de los sistemas socio-ecológicos en ocho municipios de la zona metropolitana de Mérida (Yucatán, México).

\section{Los sistemas socio-ecológicos como marco de análisis}

Para abordar la relación entre la sociedad y la naturaleza en la ciudad de Mérida y su zona metropolitana, el artículo adopta el enfoque de Sistemas Socio-Ecológicos (SSE) desarrollado por McGinnis y Ostrom (2014), por ser un marco interpretativo (Merino, 2014), que provee un lenguaje común, que permite explicar las dinámicas de cambio sociales y ambientales que enfrenta el territorio (Binder, Hinkel, Bots y Pahl-Wostl, 2013).

De acuerdo con este marco de análisis, los SSE son entendidos como un entramado de relaciones en torno a los recursos que son necesarios para la vida humana, donde interactúan variables sociales y ambientales (Anderies, Janssen y Ostrom, 2004; Ostrom 2009). Los SSE son sistemas adaptativos complejos donde agentes sociales y biofísicos interactúan y se retroalimentan en escalas múltiples temporales y espaciales (Gunderson y Holling, 2002; Holland, 2006; Janssen y Ostrom, 2006). 
En el marco de McGinnis y Ostrom (2014), los SSE son definidos a partir de las categorías: sistema de recursos, unidades de recursos, sistema de gobernanza y actores. Éstas son desglosadas en múltiples variables que permiten detallar las diferentes características del sistema (ver cuadro 1). Adicional a estas cuatro categorías, en los SSE se definen las "situaciones de acción", las cuales son sucesos o eventos que detonan cambios e interacciones en cada una de las categorías del esquema y, por ende, en la configuración del SSE.

En la Zona Metropolitana de Mérida (ZMM), las tendencias poblacionales y de desarrollo económico asociadas a los parques industriales, a la industria de la construcción y al desarrollo turístico pueden ser consideradas situaciones de acción que desaten a mediano y a largo plazos cambios estructurales en los SSE presentes en la región; de allí la importancia de realizar el análisis.

Cuadro 1. Categorías del SSE. Adaptado de McGinnis y Ostrom (2014)

\begin{tabular}{ll}
\hline Categorías del SSE & \multicolumn{1}{c}{ Variables } \\
\hline \multirow{2}{*}{ Sistema de recursos } & $\begin{array}{l}\text { Sector (pesquero, maderero, etc.), Límites de los recursos naturales, Tamaño del } \\
\text { sistema de recursos naturales, Facilidades construidas, Productividad, Propiedades } \\
\text { del equilibrio, Predicción (sistemas dinámicos), Características de almacenamiento, } \\
\text { Ubicación. }\end{array}$ \\
\hline \multirow{3}{*}{ Unidades de recurso } & $\begin{array}{l}\text { Movilidad de las unidades de recurso, Tasas de crecimiento, Interacción entre } \\
\text { unidades de recurso, Valores económicos, Número de unidades, Características } \\
\text { distintivas, Distribución espacial y temporal. }\end{array}$ \\
\hline & $\begin{array}{l}\text { Número de actores relevantes, Atributos socioeconómicos, Experiencias pasadas } \\
\text { Ubicación, Liderazgo, Normas (confianza y reciprocidad), Conocimiento del SSE, } \\
\text { Dependencia de los recursos, Tecnologías disponibles. }\end{array}$ \\
\hline Gobernanza & $\begin{array}{l}\text { Organizaciones gubernamentales, } \\
\text { Organizaciones comunitarias, Estructura de redes, Régimen de propiedad y tenencia } \\
\text { de la tierra, Reglas operacionales, Reglas colectivas, Reglas constitucionales, Reglas } \\
\text { de sanción y monitoreo. }\end{array}$ \\
\hline
\end{tabular}

Los sistemas socio-ecológicos y las zonas metropolitanas

En la actualidad existe una era de urbanización a gran escala. A nivel mundial, las zonas metropolitanas albergan a más del $50 \%$ de la población; en Europa y Norteamérica, las ciudades concentran cerca del $80 \%$ de la población; en Asia, el 50\%; y, en Latinoamérica, más del 90\% (Naciones Unidas, 2012).

En países en desarrollo, el crecimiento poblacional en las zonas peri-urbanas ejerce una fuerte transformación del paisaje rural. Por un lado, se cambia el uso de suelo favoreciendo la sobrevaloración y la privatización del territorio (Salas y Nagendra, 2014) y, por otro lado, se aumenta la presión sobre el sistema ecológico debido al alto consumo de bienes y servicios de los ecosistemas. Esto, en conjunto, conduce a un desequilibrio entre la población humana y la naturaleza (Haase, 2014; DeFries y Pandey, 2010). 
Los procesos de crecimiento urbano son un motor de cambio de uso del suelo y de las relaciones socio-ecológicas (Arnaiz-Schmitz et al., 2018) y llevan implícita la necesidad de aumentar la provisión de servicios ecosistémicos para las ciudades. Por tanto, las comunidades rurales de las zonas metropolitanas y su forma de gestionar sus recursos naturales desempeñan un papel fundamental en la preservación y en la gestión de estos servicios (Calderón, 2016).

El crecimiento urbano también puede detonar cambios en las dinámicas socioeconómicas de las comunidades que son parte de las $\mathrm{ZM}$, los cuales se manifiestan de diversas maneras: mediante la transformación de las dinámicas familiares económicoproductivas, marcadas por la reducción de los ingresos agrícolas y la diversificación de fuentes de ingresos monetarios; a partir de los intensos procesos de cambio de uso de suelo y mercado de tierras con fines habitacionales, que afectan en mayor medida a las tierras agrícolas; y por medio de los cambios culturales y sociales que se derivan de la integración de las dinámicas urbanas y rurales en un mismo espacio (Calderón y Soto, 2014). El constante aumento del tamaño de las ciudades, la demanda de servicios y la transformación del paisaje natural es hoy en día un reto para reducir el deterioro de los ecosistemas (Naciones Unidas, 2012).

El marco de Sistemas Socio-Ecológicos (SSE) ha sido utilizado para entender el estado de vulnerabilidad de las zonas metropolitanas en el mundo. Elmqvist et al. (2004) realizaron un estudio en Estocolmo, en el cual evidenciaron la importancia de los servicios ecosistémicos de los bosques que prevalecen en la $\mathrm{ZM}$ y advirtieron sobre la vulnerabilidad de estos espacios si no se contenía y planificaba el crecimiento poblacional. En Barcelona (Badía, Estany, Otero y Boada, 2010), se llevó a cabo una investigación para cuantificar las transformaciones paisajísticas de la ZM; es decir, recogía datos cartográficos y testimonios de los habitantes, teniendo como marco de análisis el de SSE.

El enfoque de SSE también ha sido utilizado para generar propuestas de proyectos que permitan una planeación urbana más sustentable, como es el caso de Biodiversidad Urbana y Servicios Ecosistémicos (URBES, por sus siglas en inglés), que se gestó luego de un análisis socioecológico del impacto del crecimiento de grandes ciudades, como Berlín, Rotterdam, Nueva York y Barcelona, en la biodiversidad circundante (Schewenius, McPhearson y Elmqvist, 2014). En el caso de México, Contreras (2016) utiliza el marco de SSE para mostrar la importancia de las áreas naturales periurbanas en la resiliencia al cambio climático de la ZM del Valle de México. 


\section{Metodología}

Zona de estudio

La zona de estudio se localiza en el sureste de México, al noroeste del estado de Yucatán; abarca la denominada Zona Metropolitana de Mérida (ZMM): Conkal, Kanasín, Progreso, Ucú y Umán, y tres municipios más hacia los cuales la ciudad está creciendo: Chicxulub Pueblo, Hunucmá y Tixpéhual (SEDUMA, 2012; Núñez et al., 2017). De esta forma, el área de estudio está integrada por Mérida y ocho municipios circundantes (ver figura 1).

Figura 1. Zona de estudio

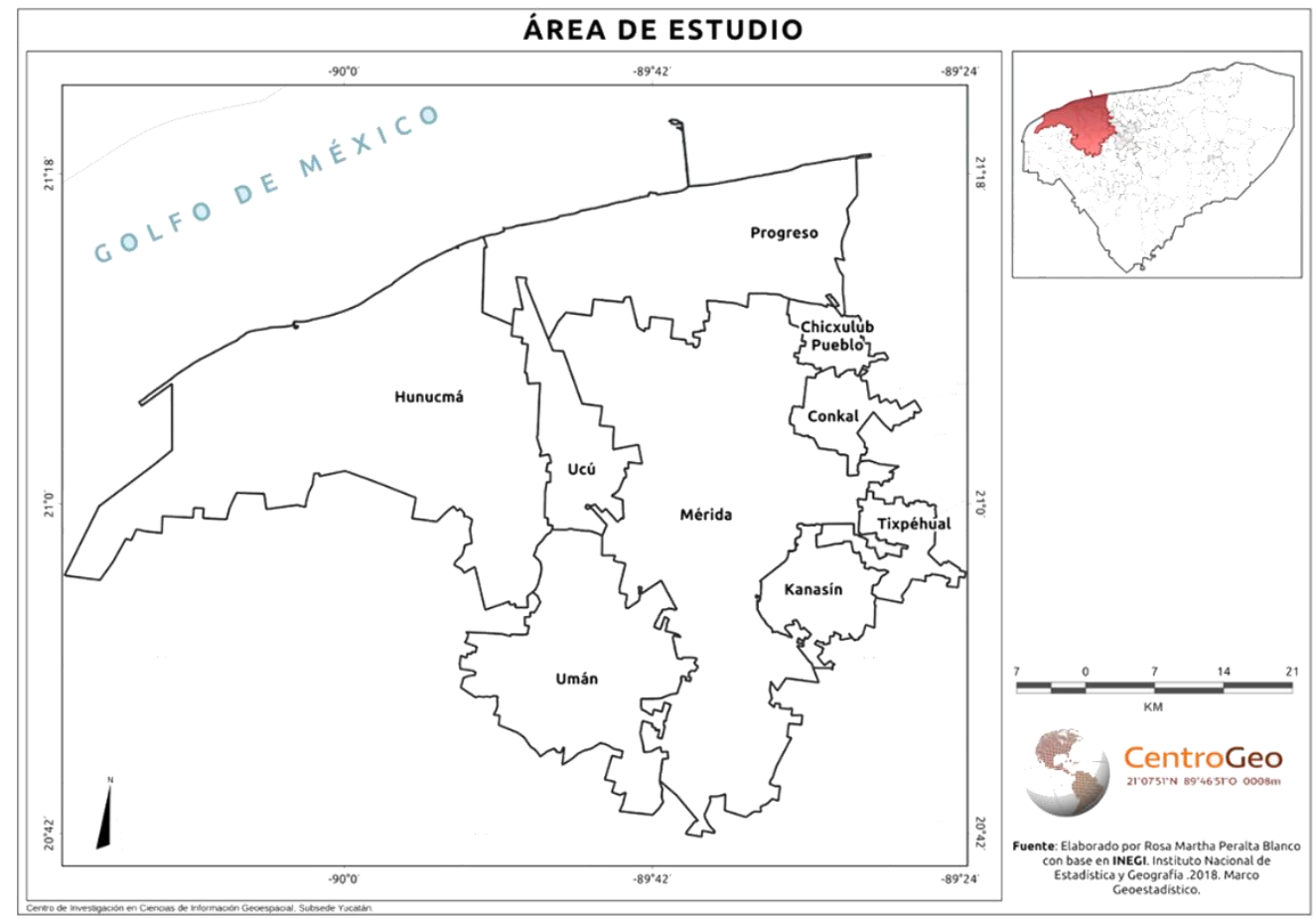

La historia natural de la Península destaca, para el estado de Yucatán, por características distintas al resto de México, como: suelo integrado por una plataforma de rocas calizas, hidrografía superficial escasa, red subterránea de cavernas y cenotes que forman parte del acuífero y de esta hidrografía, y microrelieve desde los 0 hasta los 210 msnm de altitud (Batllori y Patrón, 2002; INEGI, 2017). En particular, el noroeste de Yucatán está dominado por bosques secundarios representados por la selva baja caducifolia; un tipo de vegetación vulnerable tanto por sus endemismos como por su adaptación a los suelos calcáreos, que afronta grandes presiones antrópicas (Pérez-Sarabia et al., 2017). 
La economía de los ocho municipios se concentra principalmente en el sector secundario y terciario: industria manufacturera, construcción, extracción de materiales, transporte y comercio (INEGI, 2015). De acuerdo con la CONAPO (2010), en la zona de estudio, los niveles de marginación son muy bajo (Mérida), bajo (Progreso, Conkal, Umán y Tixpéhual) y medio (Hunucmá, Kanasín, Ucú y Chicxulub); y los niveles de pobreza son bajos, con excepción del municipio de Kanasín que está en rango medio (CONEVAL, 2015).

\section{Etapas del estudio}

La propuesta metodológica integra cuatro etapas. La primera es la visión regional del territorio a partir de información cartográfica disponible; se organizaron 17 mapas de acuerdo con las categorías del SSE: sistemas y unidades de recursos, actores y gobernanza. En cada caso se identificó la variable del sistema a la que cada mapa aporta elementos de análisis (ver cuadro 2).

En la categoría integrada de sistema y unidades de recursos se incluyeron las capas de cobertura forestal y áreas naturales protegidas, que reflejan las superficies del territorio con coberturas boscosas y bajo alguna figura de protección; se consideran aproximaciones de las características de los recursos naturales disponibles en el territorio.

En la categoría de actores, como aproximación a los medios de vida de la población en la región, se incluyó: cartografía de la superficie bajo actividad agropecuaria; número de colmenas; número de entidades (fábricas, empresas), pequeñas, medianas o grandes, asociadas al sector pesquero; porcentaje de población vinculada a cada sector económico y parques industriales de la zona de estudio.

La categoría de gobernanza representó mayores retos, como aproximación a los derechos de propiedad; se consideró cartografía de la tenencia de la tierra social, privada y federal; sin embargo, la información disponible más reciente es de 2007. Se complementó con el número de habitantes por kilómetro cuadrado y el porcentaje de población que habla lengua indígena que, aunque ofrecen elementos para el análisis de la categoría de actores, también permiten inferir en relación con los derechos de propiedad y los procesos de toma de decisiones en la región. Finalmente, se incluyeron tres mapas transversales que muestran el incremento o reducción de las coberturas (forestales y agropecuarias), así como el crecimiento de la mancha urbana en la zona de estudio. 
AÑO 22, 2020-1 ENERO-JUNIO E-ISSN 2594-102X PÁGS.97-126 DÜ:-

Cuadro 2. Aproximación cartográfica a las categorías y variables de los SSE

\begin{tabular}{|c|c|c|c|}
\hline № & Categoría del SSE & Variable del SSE & Aproximación cartográfica (mapa) \\
\hline 1 & \multirow{5}{*}{$\begin{array}{l}\text { Sistemas y unidades } \\
\text { de recurso }\end{array}$} & \multirow[t]{2}{*}{ Sectores } & Cobertura forestal en 2005 \\
\hline 2 & & & Cobertura forestal en 2015 \\
\hline 3 & & $\begin{array}{l}\text { Distribución espacial y } \\
\text { temporal de los recursos }\end{array}$ & Cambio en la cobertura forestal en 2005-2015 \\
\hline 4 & & \multirow[t]{2}{*}{$\begin{array}{l}\text { Límites territoriales del } \\
\text { recurso disponible }\end{array}$} & $\begin{array}{l}\text { Áreas Naturales Protegidas ANPs (federales, estatales } \\
\text { y municipales) en } 2005\end{array}$ \\
\hline 5 & & & ANPs y Corredor Biológico Mesoamericano en 2015 \\
\hline 6 & \multirow[t]{5}{*}{ Actores } & \multirow[t]{5}{*}{$\begin{array}{l}\text { Atributos socioeconómicos } \\
\text { y medios de vida }\end{array}$} & $\begin{array}{l}\text { Actividades agropecuarias (agricultura, pastos } \\
\text { cultivados y apicultura) en } 2005\end{array}$ \\
\hline 7 & & & Actividades agropecuarias en 2015 \\
\hline 8 & & & Cambio en las actividades agropecuarias 2005-2015 \\
\hline 9 & & & Unidades económicas pesqueras 2010-2013 \\
\hline 10 & & & $\begin{array}{l}\text { Sectores económicos } 2015 \text { y parques industriales } \\
2019\end{array}$ \\
\hline 11 & \multirow[t]{4}{*}{ Gobernanza } & Derechos de propiedad & Tenencia de la tierra 2007 \\
\hline 12 & & \multirow{2}{*}{$\begin{array}{l}\text { Dinámica en } \\
\text { concentración de } \\
\text { tenencia de la tierra }\end{array}$} & Densidad poblacional 2005 \\
\hline 13 & & & Densidad poblacional 2015 \\
\hline 14 & & $\begin{array}{l}\text { Reglas, sanciones y } \\
\text { procesos de toma de } \\
\text { decisiones }\end{array}$ & Porcentaje de Población indígena 2015 \\
\hline 15 & \multirow[t]{3}{*}{ Transversales } & & Ganancia de coberturas 2005-2015 \\
\hline 16 & & & Pérdida de coberturas 2005-2015 \\
\hline 17 & & & Crecimiento de la mancha urbana 2005-2015 \\
\hline
\end{tabular}

La segunda etapa corresponde a la búsqueda y revisión de información bibliográfica que aborde la historia de la región en torno a los sistemas y a las unidades de recursos, actores y gobernanza.

En la tercera etapa, bajo una visión local-municipal del territorio, se realizaron entrevistas a profundidad a autoridades locales clave con conocimiento de aspectos socioecológicos de la zona. El objetivo es conocer, desde su percepción, las variables asociadas al sistema y unidades de recursos, los actores y la gobernanza, como complemento a la visión regional construida cartográfica e históricamente.

Las entrevistas siguieron un formato con cuatro secciones: información general (nombre, edad, nivel de estudios, cargo, lugar de nacimiento), recursos naturales (recursos naturales disponibles, uso de las selvas y zonas de conservación), actores (actividades económicas y medios de vida primarios, secundarios y terciarios) y gobernanza (tenencia de la tierra, organizaciones, reglas, confianza). Se llevaron a cabo durante marzo-mayo de 2018; fueron grabadas y, posteriormente, consolidadas en una matriz de respuestas para facilitar el análisis. Se realizaron en total 18 entrevistas, entre dos o tres por municipio. Los actores entrevistados fueron los directores de las áreas de Desarrollo Social, Desarrollo Rural, Salud y Ecología, Desarrollo Económico y/o Comisarios ejidales (autoridades locales) en los municipios vecinos a Mérida. 
La cuarta y última etapa consiste en la integración de la información recopilada a través de cartografía, revisión bibliográfica y entrevistas, para definir la configuración de los SSE en la zona. Se seleccionaron nueve variables para analizar las estadísticas nacionales y las percepciones de la población (ver cuadro 3).

Cuadro 3. Variables comparativas de la zona de estudio

\begin{tabular}{|c|c|c|c|}
\hline $\begin{array}{l}\text { Categoría del } \\
\quad \text { SSE }\end{array}$ & Variable del SSE & Aproximación & Fuente \\
\hline \multirow[t]{3}{*}{$\begin{array}{l}\text { Sistema y } \\
\text { unidades de } \\
\text { recursos }\end{array}$} & Sector & Cobertura forestal (\%) & $\begin{array}{l}\text { Cartografía de uso del } \\
\text { suelo y vegetación de } \\
\text { INEGI } 2005 \text { y } 2015 \text {. }\end{array}$ \\
\hline & $\begin{array}{l}\text { Límites territoriales } \\
\text { del recurso disponible }\end{array}$ & $\begin{array}{l}\text { Superficie bajo área natural protegida (federal, } \\
\text { estatal, municipal) (\%) }\end{array}$ & $\begin{array}{l}\text { Cartografía a partir de } \\
\text { CONANP 2007; CONABIO } \\
\text { 2009 y 2015. }\end{array}$ \\
\hline & $\begin{array}{l}\text { Productividad del } \\
\text { sistema }\end{array}$ & $\begin{array}{l}\text { Percepción de la abundancia de recursos } \\
\text { naturales en el municipio para } \\
\text { aprovechamiento y uso. } \\
\text { Positivo (+). Los recursos son abundantes o muy } \\
\text { abundantes. } \\
\text { Negativo (-). Los recursos son pocos, muy pocos } \\
\text { o no hay. }\end{array}$ & $\begin{array}{l}\text { Entrevistas a } \\
\text { profundidad. }\end{array}$ \\
\hline \multirow[t]{3}{*}{ Actores } & $\begin{array}{l}\text { Atributos } \\
\text { socioeconómicos } \\
\text { medios de vida }\end{array}$ & $\begin{array}{l}\text { Sector (\%). Porcentaje de población } \\
\text { económicamente activa que se dedica al sector } \\
\text { primario, secundario y terciario por municipio }\end{array}$ & $\begin{array}{l}\text { Cartografía a partir de la } \\
\text { encuesta intercensal de } \\
\text { INEGI } 2015 \text {. }\end{array}$ \\
\hline & & $\begin{array}{l}\text { Sector percibido como el que ocupa a la mayor } \\
\text { cantidad de población del municipio. }\end{array}$ & $\begin{array}{l}\text { Entrevistas a } \\
\text { profundidad. }\end{array}$ \\
\hline & & $\begin{array}{l}\text { Percepción del uso de los recursos naturales en } \\
\text { el municipio. } \\
\text { Positiva (+). Se reconocen múltiples usos de los } \\
\text { recursos. } \\
\text { Negativa (-). Se resalta que los recursos se usan } \\
\text { poco, muy poco, o nada. }\end{array}$ & $\begin{array}{l}\text { Entrevistas a } \\
\text { profundidad. }\end{array}$ \\
\hline \multirow[t]{3}{*}{ Gobernanza } & $\begin{array}{l}\text { Derechos } \\
\text { propiedad }\end{array}$ & $\begin{array}{l}\text { Propiedad social (\%). Porcentaje de tierra bajo } \\
\text { propiedad social por municipio. }\end{array}$ & $\begin{array}{l}\text { Cartografía a partir de } \\
\text { INEGI, } 2007 \text {. }\end{array}$ \\
\hline & & $\begin{array}{l}\text { Venta de predios. Percepción de los procesos } \\
\text { de privatización de predios ejidales. } \\
\text { Positiva (+). Los entrevistados mencionan que } \\
\text { gran número de ejidatarios han vendido sus } \\
\text { tierras. } \\
\text { Negativa (-). Los entrevistados no hacen } \\
\text { hincapié en la venta de los predios ejidales, o } \\
\text { mencionan que se ha vendido poco. }\end{array}$ & $\begin{array}{l}\text { Entrevistas a } \\
\text { profundidad. }\end{array}$ \\
\hline & $\begin{array}{l}\text { Reglas, sanciones y } \\
\text { procesos de toma de } \\
\text { decisiones }\end{array}$ & $\begin{array}{l}\text { Población indígena (\%). Porcentaje de } \\
\text { población hablante de lengua indígena por } \\
\text { municipio }\end{array}$ & $\begin{array}{l}\text { Cartografía a partir de } \\
\text { INEGI } 2015 \text {. }\end{array}$ \\
\hline
\end{tabular}

\section{Resultados}

\section{Sistemas y unidades de recurso}

La cartografía refleja que en 2015 todos los municipios aledaños a Mérida contaban con una cobertura forestal que ocupaba entre el $35 \%$ y el $88 \%$ de su superficie. Principalmente, hay presencia de tres grupos diferentes de vegetación: al norte, vegetación costera $(35,749$ ha; $12.4 \%)$ y selva baja caducifolia $(105,381$ ha; $36.4 \%)$; , al sur, selva mediana caducifolia $(15 \% ; 42,346$ ha) (ver anexo 1 , mapa 2$)$. 
Los cambios en la cobertura forestal en el periodo 2005-2015 se concentran en tres zonas: en la costa, el cambio de vegetación primaria a secundaria; en el oriente, la reducción de la selva baja caducifolia debido al incremento de la mancha urbana; y, en la región centro-occidente, la reducción de la selva mediana caducifolia por el desarrollo de agricultura de temporal (ver anexo 1, mapa 3).

Las figuras de conservación nacionales, estatales y municipales (ver anexo 1, mapa 4) están concentradas principalmente al norte, y están representadas por la Reserva de la Biósfera Ría Celestún, las Ciénagas y los manglares de la costa norte de Yucatán y El Palmar, que juntas abarcan un área de 64,200 ha, y coinciden en el territorio con el Corredor Biológico Mesoamericano ${ }^{1}$ (Ramírez, 2003). Además, son sitios reconocidos por la Convención Ramsar sobre Humedales de Importancia Internacional (CONANP, 2014).

La revisión bibliográfica histórica para el sistema y unidades de recursos resalta que la Península de Yucatán es una región donde el vínculo entre la sociedad y la naturaleza ha permanecido por miles de años. Durante el auge de la civilización maya (periodo Clásico, hace 2300 a 2900 años) ya existían ciudades densamente pobladas, de modo que, para satisfacer sus necesidades se requería de un profundo conocimiento y uso avanzado de los recursos naturales (Wyatt, 2014).

Las selvas tropicales de Yucatán en los últimos 170 años han enfrentado grandes cambios. En la zona de estudio, se deforestaron grandes extensiones de selva baja caducifolia (Lerner et al., 1982) para dar paso al sistema de cultivo del henequén (Agave fourcroydes Lem. o Ki en maya), también conocido como agave o fibra sisal; constituida como la principal actividad económica agraria de la región y de gran relevancia en el país por más de un siglo (Baños, 1993).

Sin embargo, hacia la década de los setenta, la construcción de vialidades en el noroeste de Yucatán permitió una mejor movilidad laboral y comercial hacia los centros urbanos (Mérida y Tizimín); con ello, la pesquería a gran escala se activó, mientras que la industria henequenera decaía (Fraga, 2004). El consecuente abandono de las tierras de cultivo de henequén permitió recuperar la selva en grandes extensiones que hoy en día dominan el paisaje (González-Iturbe et al., 2002). Estas selvas son un mosaico complejo de comunidades vegetales, con presencia de cactáceas, en su mayoría endémicas (Mammillaria columbiana ssp. yucatanensis, endémica a Yucatán), que conforman la "selva baja caducifolia con cactáceas candelabriformes", la cual se desarrolla sobre un suelo único en Yucatán llamado calichal (Duno De Stefano, 2017).

${ }^{1}$ Iniciativa de cooperación cuyo objetivo es mantener la funcionalidad socio-ecosistémica de zonas de conectividad ecológica a través de la gestión territorial sostenible (EMSA, 2016). 
Actualmente, la selva baja de la península, y en especial de Yucatán, conforma el bloque continuo más grande de este tipo de vegetación en México y Centroamérica (Miles et al., 2006). Sin embargo, la conectividad de este ecosistema se encuentra amenazado debido a la urbanización y a otros cambios de uso de suelo (Maass, 1995).

A partir de las entrevistas realizadas a actores locales, se evidencia que en cinco municipios (Hunucmá, Progreso, Tixpéhual, Umán y Conkal) los recursos naturales son abundantes; es decir, se destaca la existencia de cenotes, montes y vestigios arqueológicos en buen estado de conservación y, además, todavía se pueden obtener servicios ecosistémicos. En la mayoría de los municipios donde los entrevistados manifiestan una percepción positiva, la cobertura forestal está por arriba del $40 \%$ de la superficie total del municipio; Hunucmá presenta el mayor porcentaje con $83 \%$ de cobertura y Conkal un 41\%. En el caso de Hunucmá y Progreso, los valores de cobertura forestal y la percepción positiva de abundancia y disponibilidad de recursos coinciden también con la presencia de las Áreas Naturales Protegidas, correspondiente a vegetación costera, con 52\% de superficie protegida en Hunucmá y 47\% en Progreso; en el resto de los municipios, las Áreas Naturales Protegidas no superan el $4 \%$ de su superficie, cuya vegetación dominante es la selva baja caducifolia.

En los municipios de Chicxulub Pueblo y Ucú, la cobertura forestal es más de la mitad del municipio (62\% y 88\%, respectivamente); sin embargo, los entrevistados perciben baja disponibilidad y abundancia de recursos. Finalmente, en el caso de Kanasín, la percepción negativa de disponibilidad de recursos naturales coincide con el porcentaje más bajo de cobertura forestal de todos los municipios (35\%).

\section{Actores}

Respecto a la información cartográfica sobre los medios de vida de los actores y las estrategias de diversificación y generación de ingresos, durante el periodo 2005-2015, destaca la reducción de la actividad agropecuaria en la zona (ver anexo 1, mapas 6, 7 y 8). Al norte, se presentan algunos pastizales cultivados en Chicxulub Pueblo, Conkal, Hunucmá, Progreso y Ucú (8,112 ha, el 2.8\%), bajo agricultura de riego 2 (1,541 ha, el 0.5\%); y al sur, en Umán, Tixpehual y Kanasín, bajo agricultura de temporal2 (11,151 ha; 4\%), lo cual significa que es reducida. De igual forma, hay cambios en la actividad apícola; actualmente, se observa concentrada al sur de la zona de estudio.

En relación con el desarrollo industrial, la cartografía refleja ocho parques industriales, un parque científico y la propuesta de una zona económica especial en la zona de estudio (ver anexo 1, mapa 10).

\footnotetext{
${ }^{2}$ Agricultura de riego: Agrosistemas que utilizan agua suplementaria para el desarrollo de los cultivos durante el ciclo agrícola. Agricultura de temporal: Agrosistemas en los que el ciclo depende de la precipitación pluvial y de la capacidad del suelo para retener agua (INEGI, 2009).
} 
Las estadísticas de participación de la población económicamente activa (PEA) en los tres sectores de la economía reflejan que actualmente sólo al norte, en Progreso, Chicxulub Pueblo, Hunucmá y Ucú, entre el 10\% y el 13\% de la PEA se dedican al sector primario, mientras que en los municipios restantes este porcentaje es menor. En promedio, en estos municipios cercanos a Mérida, el 29\% de la población se dedica al sector secundario y el $61 \%$ al sector terciario (ver anexo 1, mapa 10).

La historia económica de la población de la región refleja dos momentos de fuertes cambios. El punto de partida destaca la presencia de una numerosa población maya cuyos niveles de organización le permitieron generar una compleja sociedad y cultura, con la característica cosmovisión y religiosidad Mesoamericana (Bracamonte y Lizama, 2003) en la que la milpa representaba la principal forma de sustento (Guzmán-Medina, 2013). Sin embargo, al cerrarse el siglo XIX, el primer cambio surge con "La hacienda" que se convierte en la unidad de producción dominante. La llegada y auge del cultivo del henequén, cuyo producto representaba el $70 \%$ del total de mercancías enviadas al exterior (Varguéz, 1990), concentró a cerca de la mitad de la población maya en las haciendas henequeneras en calidad de peonaje asalariado (Bracamonte y Lizama, 2003).

Para 1970, más del 50\% de la población económicamente activa del estado seguía empleada en la agricultura y el henequén representaba más del 50\% de la tierra cultivada y el 60\% de la producción agrícola total (Baños, 1996; Castilla-Ramos, 1991).

De acuerdo con Ramírez (2000), ante la posterior caída del cultivo y la producción de fibra de henequén en Yucatán, se genera un segundo cambio "la industria y la maquila". En el periodo 1973-1984 se establecen cuatro parques industriales en la zona metropolitana de Mérida: "Felipe Carrillo Puerto" (160 ha), "Yucalpetén" (120 ha), "Parque industrial Yucatán" (198 ha) y el "Polígono industrial" (88 ha). Posteriormente, el número de parques industriales en la zona metropolitana se incrementa a siete.

Asimismo, se impulsó la operación de maquiladoras de exportación. En 1995, en 37 establecimientos laboraban 6,000 personas y 33 de los 37 establecimientos se ubicaban en la conurbación Mérida-Progreso (Ramírez, 2000).

En este tránsito a los sectores secundario y terciario, Yucatán se posicionó como uno de los principales productores de carne de cerdo y aves (SIAP 2016), concentrando la zona metropolitana diversas granjas con avicultura y porcicultura tecnificada. Hunucmá, Progreso y Umán han sobresalido en producción avícola y porcícola; Chicxulub Pueblo, en producción avícola; y, Conkal, en actividad porcícola. De acuerdo con Domínguez (2011) en sólo 30 años, el patrón de la economía predominantemente agrícola de los municipios aledaños a Mérida cambió. 
Otro aspecto productivo importante en la región es la extracción de recursos pesqueros. Históricamente, los municipios de Progreso y Hunucmá han tenido esta actividad como un medio de subsistencia y, hasta la década de los ochenta, la población estaba dedicada, en su mayoría, al henequén y, en menor medida, a la sal artesanal y cacería de fauna silvestre (Fraga, 2004).

Hacia la década de los setenta, las vías de comunicación, tanto marítimas como terrestres, detonaron en el litoral yucateco la pesca industrial de especies de la franja marina que, en la actualidad, se perciben como íconos municipales (pulpo maya y mero) (Salas et al., 2006). En el periodo 2004-2013, Yucatán obtuvo una importante producción pesquera promedio de 329,220 \pm 89,491 Ton de peso vivo, colocándose en el séptimo lugar a nivel nacional (CONAPESCA, 2013). En ese tiempo, la flota pesquera yucateca contaba con una población de 11,180 pescadores, 509 embarcaciones mayores activas, 2,564 embarcaciones ribereñas activas, 48 plantas pesqueras y 131 unidades de producción acuícola.

Los resultados de las actividades económicas y medios de vida descritos a partir de la cartografía y de la revisión bibliográfica se complementan con las entrevistas, pues éstas reportan hasta siete usos de los recursos naturales: pesca, recolección de leña, extracción de madera para construcción, aprovechamiento de insumos para artesanías, cacería, extracción de plantas medicinales y apicultura. Si bien Hunucmá y Progreso son los únicos que presentan pesca, Hunucmá,Tixpehual y Umán informan el número máximo de usos (5), y Progreso y Kanasín sólo dos usos.

Los entrevistados de Hunucmá y Progreso son los únicos que perciben al sector primario como actividad económica principal $\mathrm{y}$, efectivamente, son los municipios con más altos porcentajes dentro de este sector (>10\%, ver anexo 1, mapa 10). En el resto de los municipios, la percepción coincide con las estadísticas recayendo la concentración de la población en los sectores económicos secundario y terciario. Este aspecto es complementado con la mención recurrente de la migración interna de la población hacia Mérida para trabajar en actividades como albañilería, transporte, comercio y servicios.

\section{Gobernanza}

Con relación a la distribución de la tenencia de la tierra en la ZMM, los datos más recientes se remontan a 2007. Los resultados en el análisis cartográfico (ver anexo 1, mapa 11) reflejan que la propiedad federal (asociada a las ANPs) está concentrada, principalmente, al norte de Hunucmá, Ucú y Progreso. Esta zona también presenta franjas de propiedad privada en toda la línea costera de Hunucmá y Progreso. 
Por otra parte, la propiedad privada en el resto de la ZMM se encuentra como un mosaico de parches dispersos y embebidos en la propiedad social (ejidos); ésta última es la forma de tenencia de la tierra que predomina, con una superficie de 171,576 ha, corresponden al 59.4\% del total del territorio comprendido por la ZMM.

Respecto a la densidad poblacional, la cartografía no refleja cambios en en el periodo 2005-2015 (ver anexo 1, mapas 12 y 13); sin embargo, evidencia que Kanasín y Mérida son los dos municipios que, a lo largo de esos 10 años, han permanecido con las densidades más altas de población $\left(>174 \mathrm{hab} / \mathrm{km}^{2}\right)$, seguidos en orden decreciente de Umán, Progreso, Conkal (entre 99 y 174 hab/ km²), Chicxulub pueblo y Tixpehual (entre 38 y $\left.99 \mathrm{hab} / \mathrm{km}^{2}\right)$; finalmente, Hunucmá y Ucú han permanecido con las más bajas densidades de población en la ZMM $\left(<39\right.$ hab $\left./ \mathrm{km}^{2}\right)$.

En cuanto a la presencia de población indígena en el 2015 (ver anexo 1, mapa 14), representada por la etnia maya, en la ZMM, Ucú, tiene el más alto porcentaje (54\%) con respecto al total de su población. En contraste, los municipios de Kanasín y Mérida, es decir, los más densamente poblados, también presentan los más bajos porcentajes de población indígena $(<14 \%)$.

Los resultados de la revisión bibliográfica para la tenencia de la tierra revelan que los procesos de privatización en la ZMM han sido potenciados por los gobiernos estatal y federal a través de iniciativas como el Programa Nacional de Desmonte, el cual entró en operación en la década de los setenta y dejó sin vigencia algunos principios asociados a la tenencia colectiva (Torres-Mazuera, 2016). Aunado a ello, la reforma al artículo 27 constitucional, en 1992, permitió la privatización de los ejidos, lo que abrió la posibilidad de la incorporación de la propiedad social al crecimiento urbano y derivó en una dinámica de expansión territorial difusa y segregada de las áreas periurbanas (Olivera, 2015). Por otra parte, el área donde actualmente se asienta la ZMM ha sufrido transformaciones fuertes derivadas de la deforestación y el establecimiento de plantíos henequeneros en el siglo pasado (Faust, 2001), lo cual ha ocasionado la pérdida de fertilidad de la tierra y, por ende, de su productividad, por lo que su valor ya no está asociado a la actividad primaria, sino que recae en la posibilidad de su venta.

Respecto al crecimiento demográfico en la ZMM, condensado principalmente en Mérida y Kanasín, la literatura asocia este fenómeno a la tendencia histórica de la concentración de la economía en la ciudad central (Mérida) que, a su vez, propició desarrollo y modernización en la infraestructura de transporte y comunicación a su zona periférica, sobre todo al sur (Bolio, 2014). En Kanasín se ha configurado una de las principales "ciudades dormitorio", es decir, un espacio económicamente accesible donde habitan las personas que conforman una buena parte del recurso humano para el sector secundario y terciario en Mérida (Ramírez y López, 2014). 
Por otra parte, los datos de la escasa presencia de población indígena en la ZMM se enmarcan en una segregación histórica en la región asociada a una demarcación de fronteras socioculturales muy rígidas entre Mérida y sus alrededores (llamado el noroeste "blanco") y el resto indígena del territorio peninsular (Bolio, 2014).

Los datos obtenidos de las entrevistas para conocer la percepción asociada a los procesos de privatización de la tierra señalan que esta percepción es positiva en seis de los municipios de la zona de estudio (Chicxulub Pueblo, Conkal, Kanasín, Progreso, Tixpehual y Ucú); es decir, los entrevistados perciben que gran parte de la tierra de su municipio ha sido vendida, sobre todo a empresas inmobiliarias, lo cual denotan con expresiones recurrentes como "ya todo está vendido". Sin embargo, Umán y Hunucmá son la excepción, pues la venta de predios es mínima o no fue mencionada.

\section{Configuración de los SSE en el AM de Mérida}

Los cambios recientes (2005-2015) en el área de estudio destacan principalmente dos ganancias y tres pérdidas de cobertura. Las primeras se evidencian en la expansión de la mancha urbana $(27,318$ ha; $9.4 \%)$ y el establecimiento de pastizales cultivados $(9,099$ ha; $3.2 \%)$ al norte de Hunucmá. Las segundas son: la reducción de la superficie agrícola (21,680 ha; 7.5\%), la reducción de la selva mediana caducifolia $(20,507$ ha; $7.1 \%)$ y la disminución de la selva baja caducifolia (24,736; 8.6\%) (ver anexo 1, mapas 15, 16 y 17). Estos cambios, junto con las evidencias históricas, las entrevistas a actores clave y la cartografía, permiten identificar interacciones sociedad-naturaleza y advierten la presencia de SSE (ver figura 2).

A partir de los resultados del análisis de las categorías de los SSE de McGinnis y Ostrom (2014), se elaboró una propuesta cartográfica donde fueron definidos dos SSE predominantes para la zona de estudio; separados entre sí por una zona de transición. La delimitación fue producto del uso de recursos geoespaciales basados en análisis espacial ${ }^{3}$ con Sistemas de Información Geográfica (GIS por sus siglas en inglés).

Así, por medio de operaciones geométricas con datos vectoriales ${ }^{4}$ y análisis de combinación o superposición ${ }^{5}$ fueron delimitados los dos SSE. El primero se localiza al norte de la zona de estudio (Región Norte), cuya delimitación se define biofísicamente por la predominancia de vegetación de selva baja y costera asociada al manglar, tular, petén, vegetación halófila, hidrófila y dunas (ver anexo 1, mapa 2).

\footnotetext{
3 “Estudio cuantitativo de fenómenos que se manifiestan en el espacio” (Olaya, 2014; Anselin, 1989).

${ }^{4}$ Operaciones que modifican, combinan y analizan geometrías que aportan información complementaria o procesan datos para otros análisis: pueden ser de influencia, operaciones de solape, conjunción de capas, modificaciones basadas en atributos, entre otros (Olaya, 2014).

${ }^{5}$ Metodologías de integración de variables geográficas orientadas a una temática para obtener nuevos datos geográficos (Olaya, 2014).
} 
El límite de la Región Norte se define al sur a partir de áreas donde la influencia de la expansión urbana se fortalece debido al próximo desarrollo inmobiliario habitacional de Mérida. De dicha disrupción entre el SSE y las áreas susceptiblemente urbanas surge una zona de transición., la cual se localiza en el área central de la ZM de Mérida y se caracteriza por dinámicas de cambio en la cobertura forestal en dos sentidos: la disminución de selva mediana por selva baja caducifolia y su decremento a favor del crecimiento de la ciudad de Mérida (ver anexo 1, mapas 15, 16 y 17). La zona de transición es el escenario de crecimiento de la mancha urbana, de concentración de estrategias de desarrollo económico y el motor de cambio para las Regiones Norte y Sur.

A nivel socioeconómico, el SSE se caracteriza por la presencia de actividades primarias: pesca, apicultura, ganadería en pastizales cultivados y agricultura de riego; secundarias: elaboración de artesanías con conchas, coco, henequén o madera de chacá; y terciarias: turismo; especialmente, en los puertos de Progreso y Sisal (ver anexo 1, mapas 7, 9 y 10).

El segundo SSE se localiza al sur de la zona de estudio (Región Sur) y se encuentra delimitado biofísicamente a partir de la vegetación secundaria de selva mediana (ver anexo 1, mapa 2) y de las actividades económicas primarias relacionadas con la agricultura de temporal y apicultura (ver anexo 1, mapa 7). Al norte limita con la zona de transición, la mancha urbana y el área de influencia de los desarrollos inmobiliarios habitacionales del sur de Mérida y Kanasín.

Figura 2. Sistemas socio-ecológicos en el AM de Mérida

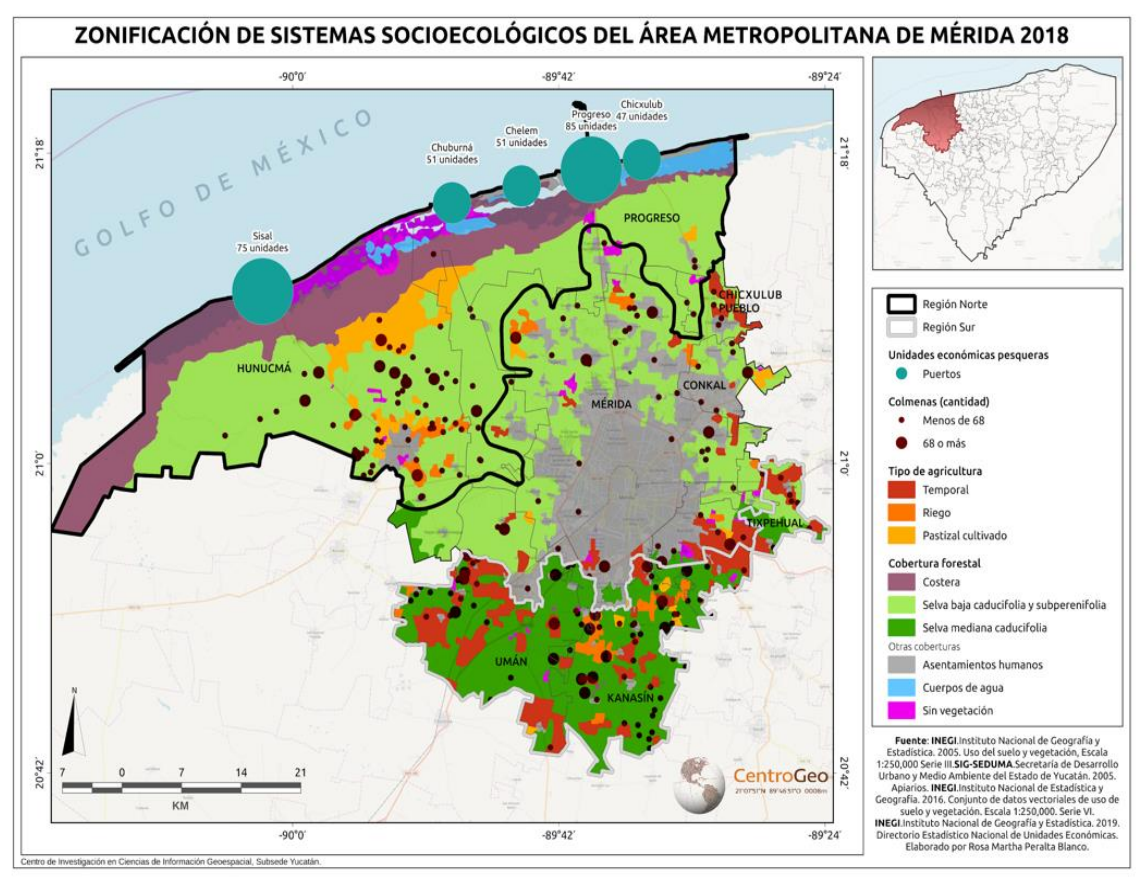




\section{Discusión y conclusión}

La zona de estudio está marcada por cambios importantes que han incidido en el sistema, las unidades de recursos, los actores y la gobernanza. La historia de la zona destaca fuertes procesos de deforestación (Lerner et al. 1982) y diferentes periodos de impulso de los tres sectores productivos (Varguéz, 1990; Ramírez, 2000; Bracamonte y Lizama, 2003); determinantes de la actual configuración de los sistemas socio-ecológicos en la zona metropolitana.

La relación sociedad-naturaleza se ha reconfigurado; las necesidades de la población han cambiado; la creciente venta de terrenos a las empresas inmobiliarias, asociada a la diversificación de las actividades económicas con tendencia a los sectores secundario y terciario, ha desencadenado nuevas relaciones con la tierra y ha promovido una transformación rural-urbana. Baños (1993) hace referencia a la presencia en Yucatán de comunidades campesinas culturales (comunidades milperas o henequeneras) que, a lo largo del proceso de urbanización, se han transformado en comunidades satélites enfocadas a las actividades económicas secundarias y terciarias predominantes.

Esta transformación rural-urbana se explica, en parte, por los atributos de la gobernanza de los SSE. El cambio de la tenencia de la tierra, de propiedad ejidal a privada, generalmente, deviene en una expansión segregada de las zonas urbanas y en la formación de espacios carentes de servicios, de convivencia social y de apropiación de espacios públicos (Olivera, 2015). Por otra parte, las inconsistencias de las legislaciones que rigen el territorio estimulan la venta de predios ejidales a desarrolladores inmobiliarios.

En este sentido, la gobernanza del territorio se reconfigura y el destino de las tierras ya no estará en manos de las instituciones ejidales, sino que estará decidido por los mismos desarrolladores (Jiménez y Ayala, 2014). Este fenómeno se replica a lo largo de otras ZMM del mundo, específicamente en Berlín, Rotterdam, Nueva York y Barcelona; de acuerdo con los resultados de Schewenius et al. (2014), la planeación débil del crecimiento urbano vulnera el bienestar de las poblaciones que habitan en las ZMM y evidencia como un reto el fortalecimiento de la gobernanza local para evitarlo.

Los resultados reportan ganancias en la superficie forestal; sin embargo, éstos pueden ser interpretados equívocamente. En este estudio de caso, la abundante cobertura forestal está asociada al abandono de las actividades agrícolas (henequén, agricultura de riego y de temporal) y a la venta de predios; por tanto, es una variable que requiere ser constantemente monitoreada, pues puede presentar cambios drásticos de acuerdo con las tendencias de crecimiento de la ciudad. 
De esta forma, la diferencia entre ganancia y pérdida de cobertura evidencia pérdida neta de superficie forestal (selva baja y mediana caducifolia) y agrícola para la ampliación de la mancha urbana (Heynen y Robbins, 2005). Sin embargo, las tendencias de Mérida reflejan una fuerte dinámica de cambio, asociada al desarrollo de nuevos parques industriales y de nuevos fraccionamientos, identificados a través de las entrevistas y de la documentación (SEDUMA, 2007). Los resultados, a partir del enfoque de SSE, permitieron resaltar la presencia de dos sistemas socio-ecológicos: uno, en el norte relacionado, principalmente, con la pesca, la apicultura y el turismo; $y$, otro, en el sur vinculado con la apicultura y la agricultura de temporal.

Estos SSE requieren ser sostenidos, es decir, que se respete el vínculo sociedadnaturaleza y se reconozcan y dignifiquen los servicios que la actividad pesquera, agropecuaria y de conservación de los bosques y selvas proveen a la zona de transición, pues son elementos clave para la consolidación de sistemas agroalimentarios sostenibles en la zona metropolitana.

Para Tomao et al. (2017), es relevante delimitar zonas de conservación que provean servicios ecosistémicos y contengan estratégicamente el territorio ante la creciente venta de predios y posible deforestación (Salas y Nagendra, 2014), como consecuencia de la vocación del suelo (suelo urbano e industrial de transformación, descrito en el Plan de ordenamiento ecológico territorial del estado de Yucatán (POETY) (SEDUMA, 2007).

El reto es reconocer y entender las características, tanto de la zona de transición como de los SSE circundantes, para que las tendencias poblacionales y de desarrollo económico que sigue Mérida no conlleven al final deterioro de la relación sociedadnaturaleza prevaleciente en la región. De esta forma, el documento ofrece una primera aproximación al estado actual de las variables del sistema y unidades de recurso, actores y gobernanza. El siguiente paso consiste en analizar las interacciones y los resultados de las categorías de los SSE bajo los diversos escenarios de cambio que enfrenta la zona de transición, los cuales representan metamorfosis sociales y ambientales que impactan en los ecosistemas e inciden en la cultura, en las relaciones de poder y en las actividades económicas (Salas-Zapata et al., 2012).

Finalmente, el análisis de los SSE en la zona metropolitana de Mérida, con base en cartografía y en entrevistas, permitió conocer, a partir de escalas diferenciadas, algunos elementos que definen los SSE presentes. Si bien la cartografía (no siempre actualizada) delimitó con un enfoque regional las coberturas forestales y las actividades primarias de los SSE, las entrevistas precisaron el uso actual de los recursos naturales, la importancia de los sectores secundario y terciario en las actividades económicas y la creciente venta de predios en la zona de estudio. 
La principal fortaleza en el uso del marco consistió en considerar desde un inicio una amplia gama de variables sociales y ambientales para caracterizar los SSE; sin embargo, la adaptación del marco para la escala regional resultó compleja, especialmente en la categoría de gobernanza; por otra parte, se identificaron variables que, de acuerdo con la perspectiva, pueden ubicarse en una $u$ otra categoría, lo que puede conducir a confusiones.

\section{Agradecimientos}

Agradecemos a las autoridades locales y a funcionarios públicos que amablemente accedieron a ser entrevistados y a compartir la experiencia de sus municipios con el equipo de trabajo. Agradecemos también los valiosos aportes de los dos revisores del artículo, cuyos comentarios favorecieron la calidad del artículo.

\section{Referencias}

Anderies, J., Janssen, M. y Ostrom, E. (2004). A framework to analyze the robustness of social- ecological systems from an institutional perspective. Ecology and Society, 9(1), 18 . Recuperado de: http:/ /www.ecologyandsociety.org/vol9/iss1/art18/

Anselin, L. (1989). What is special about spatial data? Alternative perspectives on spatial data analysis. In Symposium on Spatial Statistics, Past, Present and Future. Department of Geography, Syracuse University.

Arnaiz-Schmitz, C., Schmitz, M., Herrero-Jáuregui, C., Angonese, J. y Pineda, F. (2018). Identifying socioecological networks in rural-urban gradients: Diagnosis of a changing cultural landscape. Science of the Total Environment, 612, 625-635. 10.1016 doi:http://10.1016/j.scitotenv.2017.08.215

Badía, A., Estany, G., Otero, I. y Boada, M. (2010). Estudio del crecimiento urbano disperso y los cambios en el paisaje en Matadepera (Región Metropolitana de Barcelona). Boletín de la asociación de Geógrafos Españoles, 54, 301-321. Recuperado de: https:/ / dialnet.unirioja.es/servlet/articulo?codigo=3605490

Baños, O. (1993). Reconfiguración rural-urbana en la Zona henequenera de Yucatán. Estudios Sociológicos, 11(32), 419-443.

Baños, O. (1996). Neoliberalismo, reorganización y subsistencia rural: el caso de la zona henequenera de Yucatán, 19801992. Mérida: Universidad Autónoma de Yucatán.

Batllori, S. y Febles-Patrón, J. L. (2002). El agua subterránea en el desarrollo regional de la península de Yucatán. Avance y Perspectiva, 21, 67-77.

Binder, C., Hinkel, J., Bots, P. \& Pahl-Wostl, C. (2013). Comparison of frameworks for analyzing socialecological systems. Ecology and Society, 18(4), 26.

Bolio, J. (2014). Mérida metropolitana. Evolución histórica y rasgos actuales-una perspectiva urbana. En: López, R. y Ramírez, L. (Ed.) Crecimiento urbano y cambio social: escenarios de la transformación de la zona metropolitana de Mérida. Mérida: Centro Peninsular en Humanidades y Ciencias Sociales / Universidad Nacional Autónoma de México

Bracamonte, P. y Lizama, J. (2003). Marginalidad indígena: una perspectiva histórica de Yucatán. Desacatos, 13, 83-98. Recuperado de: https://www.redalyc.org/pdf/139/13901306.pdf

Calderón, A. y Soto, L. (2014). Transformaciones agrícolas en el contexto periurbano de la ciudad de San Cristóbal de Las Casas, Chiapas. Limina R, 12(1), 125-143.

Calderón, R. (2016). El rol de las Áreas Naturales Periurbanas para la resiliencia al Cambio Climático de las Metrópolis: el caso de la ciudad de México. Revista Iberoamericana de Economía Ecológica, 25, 69-79.

Castilla-Ramos, B. (1991). La ocupación en Yucatán. Mérida: Universidad Autónoma de Yucatán. 
CONANP. (2014). Catálogo de metadatos geográficos. Comisión Nacional para el Conocimiento y Uso de la Biodiversidad. Sitios RAMSAR de México 2014, escala 1:0. Recuperado de: http://www.conabio.gob.mx/informacion/metadata/gis/ramsar14gw.xml?_httpcache=yes\&_xsl=/db/ metadata/xsl/fgdc_html.xsl\&_indent=no

CONAPESCA. (2013). Anuario Estadístico de Acuacultura y Pesca. Recuperado de:https:/ / www.gob.mx/conapesca/documentos/anuario-estadistico-de-acuacultura-y-pesca.

CONAPO. (2010). Índice de marginación por entidad federativa y municipio 2010. Recuperado de: http:/ / www.conapo.gob.mx

CONEVAL. (2015). Porcentaje de la población en situación de pobreza 2015. Recuperado de: https://www.coneval.org.mx/coordinacion/entidades/Yucatan/Paginas/pobreza_municipal2015.aspx.

Contreras, R. (2016). El rol de las áreas naturales periurbanas para la resiliencia al cambio climático de las metrópolis: el caso de la Ciudad de México. REVIBEC-Revista Iberoamericana de Economía Ecológica, 25, 6979. Recuperado de: https:/ / dialnet.unirioja.es/servlet/articulo?codigo $=5571695$

Defries, R. y Pandey, D. (2010). Urbanization, the energy ladder and forest transitions in India's emerging economy. Land Use Policy, 27(2), 130-138.

Domínguez, M. (2011). Avances en el estudio de la estructura territorial de la zona metropolitana de Mérida, Yucatán. Península, 6(1), 185- 200.

Duno de Stefano, R. (2017). El caliche yucateco, una vegetación compleja que falta por estudiar y definir. Desde el Herbario CICY, 9, 231-235.

Elmqvist, T., Colding, J., Barthel, S., Borgström, S., Duit, A., Lundberg, J. y Andersson, E., Ahrné, K., Ernston, H., Folke, C. y Bengtosson, J. (2004). The dynamics of Social-Ecological systems in urban landscapes: Stockholm and the national urban park, Sweden Annals of the New York Academy of Sciences, 1023(1), 308322.

EMSA (2016). Plan Director Corredor Biológico Centroamericano 2020. Gestión territorial sostenible en el Corredor Biológico Mesoamericano. Recuperado de: http://www.proyectomesoamerica.org/index.php

Faust, B. (2001). Maya environmental successes and failures in the Yucatan Península. Environmental Science $\mathcal{E}$ Policy, 4, 153-169.

Fraga, J. (2004). Los habitantes de la zona costera de Yucatán: entre la tradición y la modernidad. En: E. Rivera Arriaga, G. J. Villalobos, I. Adeath y F. Rosado (Eds.). El manejo costero en México. México: Universidad Autónoma de Campeche, SEMARNAT, CETYS-Universidad, Universidad de Quintana Roo.

González-Iturbe, J., Olmsted, I. y Tun Dzul, F. (2002). Tropical dry forest recovery after long term Henequen (sisal, Agave fourcroydes Lem.) plantation in northern Yucatan, Mexico. Forest Ecology and Management, $167,67-82$.

Graizbord, B. y Pérez-Torres, D. (2012). Megacities, metropolitan areas, and local governments: The Mexican experience. Centro de Estudios Demográficos Urbanos y Ambientales. Documento de Investigación No. 7, CEDUA-COLMEX. Recuperado de: http://biblioteca.clacso.edu.ar/Mexico/ceduacolmex/20170418025657/pdf_801.pdf

Gunderson, L. y Holling, S. (2002). Panarchy: Understanding Transformations in Human and Natural Systems. Washington, DC: Island Press.

Guzmán-Medina, V. (2013). Lengua e identidad entre los mayas contemporáneos de Yucatán. Anales de Antropología, 47(1), 57-71.

Haase, D. (2014). The nature of urban land use and why it is a special case. En K. Seto, A. Reenberg (Eds.). Rethinking global land use in an urban era. Cambridge MA: MIT Press, Strüngmann Forum Reports.

Heynen, N. y Robbins, P. (2005). The Neoliberalization of Nature: Governance, Privatization, Enclosure and Valuation. The Center of Political Ecology. Symposium. Capitalism Nature Socialism. 16(1), 1-8. DOI: $10.1080 / 1045575052000335339$.

Holland, J. H. (2006). Studying Complex Adaptive Systems. Journal of Systems Science and Complexity, 19(1), 18.

INEGI (1970). IX Censo General de Población 1970. 28 de enero de 1970. Estado de Yucatán. Recuperado de: https://www.inegi.org.mx/app/biblioteca/ficha.html?upc=702825413484 
INEGI (2009). Diccionario de datos uso del suelo y vegetación. Escala 1:250.000. Recuperado de: http://www.inegi.org.mx/geo/contenidos/recnat/usosuelo/doc/dd_usyv_v3_250k.pdf

INEGI (2015). Encuesta intercensal 2015. Recuperado de: http://www.beta.inegi.org.mx/proyectos/enchogares/especiales/intercensal/

INEGI (2017). Anuario estadístico y geográfico de YUcatán. 2017. Recuperado de: https://www.datatur.sectur.gob.mx/ITxEF_Docs/YUC_ANUARIO_PDF.pdf

Janssen, M. y Ostrom, E. (2006). Governing social-ecological systems. En: L. Tesfatsion, J. Kenneth (Eds.). Handbook of Computational Economics 2. Elsevier B.V.A, 1465-1502.

Jiménez, E. y Ayala, A. (2014). Los Ejidos y comunidades indígenas ante la expansión de Guadalajara, 19202000. En Olivera, G. (Coord.) La organización social y privada del ejido. Ensayos sobre la dualidad del desarrollo urbano en México. Mexico, D.F.: Universidad Nacional Autónoma del México.

Lerner, S., Saavedra, F., Quesnel, A. y Séller, L. (1982). Análisis de los datos del estudio sociodemográfico de la población de la zona Henequenera del estado de Yucatán. Mérida, México: El Colegio de México.

López-Santillán, 2011. R. (2011). La metrópoli Meridana, principales tendencias socioespaciales. Península, 6(1), 47-81.

Maass, M. (1995). Conversion of tropical dry forest to pasture and agriculture. En: S. Bullock, H. Mooney \& E. Medina (Eds.) Seasonally Dry Tropical Forest. Cambridge: Cambridge: Univesrity Press, 399-436.

McGinnis, M. y Ostrom, E. (2014). Social-Ecological system framework: Initial changes and continuing challenges. Ecology and Society, 19(2), 30.

Merino, L. (2014). Perspectivas sobre la gobernanza de los bienes y la ciudadanía en la obra de Elinor Ostrom. Revista Mexicana de Sociología, 76, 77-104.

Miles, L., Newton, A., Defries, R., Ravilious, C., May, I., Blyth, S., Kapos, V. \& Gordon, J. (2006). A global overview of the conservation status of Tropical Dry Forest. Journal of Biogeography, 33, 491-505.

Naciones Unidas. (2012). World urbanisation prospects the 2011 revision. Recuperado de: http://www.un.org/en/development/desa/publications/world-urbanization-prospects-the-2011revision.html

Núñez, J., Corona, N., Ocampo, P. y Mohar, A. (2017). Conectando el frente de agua marítimo de la zona costera norte de Yucatán con la zona metropolitana de Mérida. En: A. Iracheta, C. I. Pedrotti., P. Rodríguez Alomá (Coord.). Debate y propuestas en Iberoamérica. Suelo urbano y frentes de agua. México: El Colegio Mexiquense.

Olaya, V. (2014). Sistemas de Información Geográfica. Recuperado de: https://archive.org/details/SistemasDeInformacionGeografica/page/n3

Olivera, G. (2015). La urbanización social y privada del ejido. Ensayos sobre la dualidad del desarrollo urbano en México. México: Universidad Nacional Autónoma de México.

Ostrom, E. (2009). A General Framework for Analyzing Sustainability of Social-Ecological Systems. Science, (325)5939, 419-422.

Pérez-Sarabia, J., de Stefano, R., Fernández-Concha, C., Ramírez Morillo, I., Méndez Jiménez, N., Zamora Crescencio, P., Gutiérrez Báez, C. y Cetzal Ix, W. (2017). El conocimiento florístico de la Península de Yucatán, México. Polibotánica, 44, 39-49.

Ramírez, G. (2003). El Corredor Biológico mesoamericano. BioDiversitas, 47,1-3.

Ramírez, L. (2000). Historia Regional de Yucatán. Perfil Socioeconómico. México: Editorial Limusa- CONALEPSEP.

Salas, S., Mexicano-Cíntora, G., y Cabrera, M. A. (2006). ¿Hacia dónde van las pesquerías en Yucatán? Tendencias, Retos y Perspectivas. Mérida: CINVESTAV Unidad Mérida

Salas-Zapata, W.A., Ríos-Osorio, L.A y Álvarez-Del Castillo, J. (2012). Marco conceptual para entender la sustentabilidad de los sistemas sociecológicos. Ecología actual. 22(1):74-79.

Schewenius, M., McPhearson, T. y Elmqvist, T. (2014). Opportunities for increasing resilience and sustainability of urban social-ecological systems: insights from the URBES and the cities and biodiversity outlook projects. Ambio, 43(4), 434-444. 
SEDUMA. (2012). Zona Metropolitana de Mérida. Gobierno del Estado de Yucatán. Poder Ejecutivo. Recuperado de: http://www.seduma.yucatan.gob.mx/desarrollo-urbano/zona-metropolitana-merida.php

SEDUMA. (2007). Programa de Ordenamiento Ecológico Territorial del Estado de Yucatán. Recuperado de: http://sds.yucatan.gob.mx/archivos/legislacion-fija/DECRETO-POETY.pdf

SIAP. (2016). Atlas agroalimentario 2016. Recuperado de: http://nube.siap.gob.mx/gobmx_publicaciones_siap/pag/2016/Atlas-Agroalimentario-2016

Sturzacker, J. y Mell, I. (2017). Green belts? past; present; future? New York: Routledge, 102.

Tomao, A., Quatrini, V., Corona, P., Ferrara, A: Lafortezza, R. y Salvati, L. (2017). Resilient landscapes in Mediterranean urban areas: Understanding factors influencing forest trends. Environmental Research. 156,1-9.

Torres-Mazuera, G. (2016). La común anomalía del ejido posrevolucionario. Disonancias normativas y mercantilización de la tierra en el sur de Yucatán. México: Centro de Investigaciones y Estudios Superiores en Antropología Social.

Salas, H. y Nagendra, H. (2014). Privatizing the commons: impact on ecosystem services in Bangalore's lakes. Urban Ecosystems, 18(2), (613-632.

Varguéz, L. (1990). Mérida. Algunos aspectos de su transformación y perspectiva actual. Mérida: Universidad Autónoma de Yucatán, Centro de Investigaciones Regionales.

Wyatt, A. (2014). The scale and organization of ancient Maya water management. Water, 1(5), 449-467. 


\section{Anexo 1}

Cartografía del sistema y unidades de recursos al noroeste de Yucatán

Mapa 1. Cobertura forestal 2005

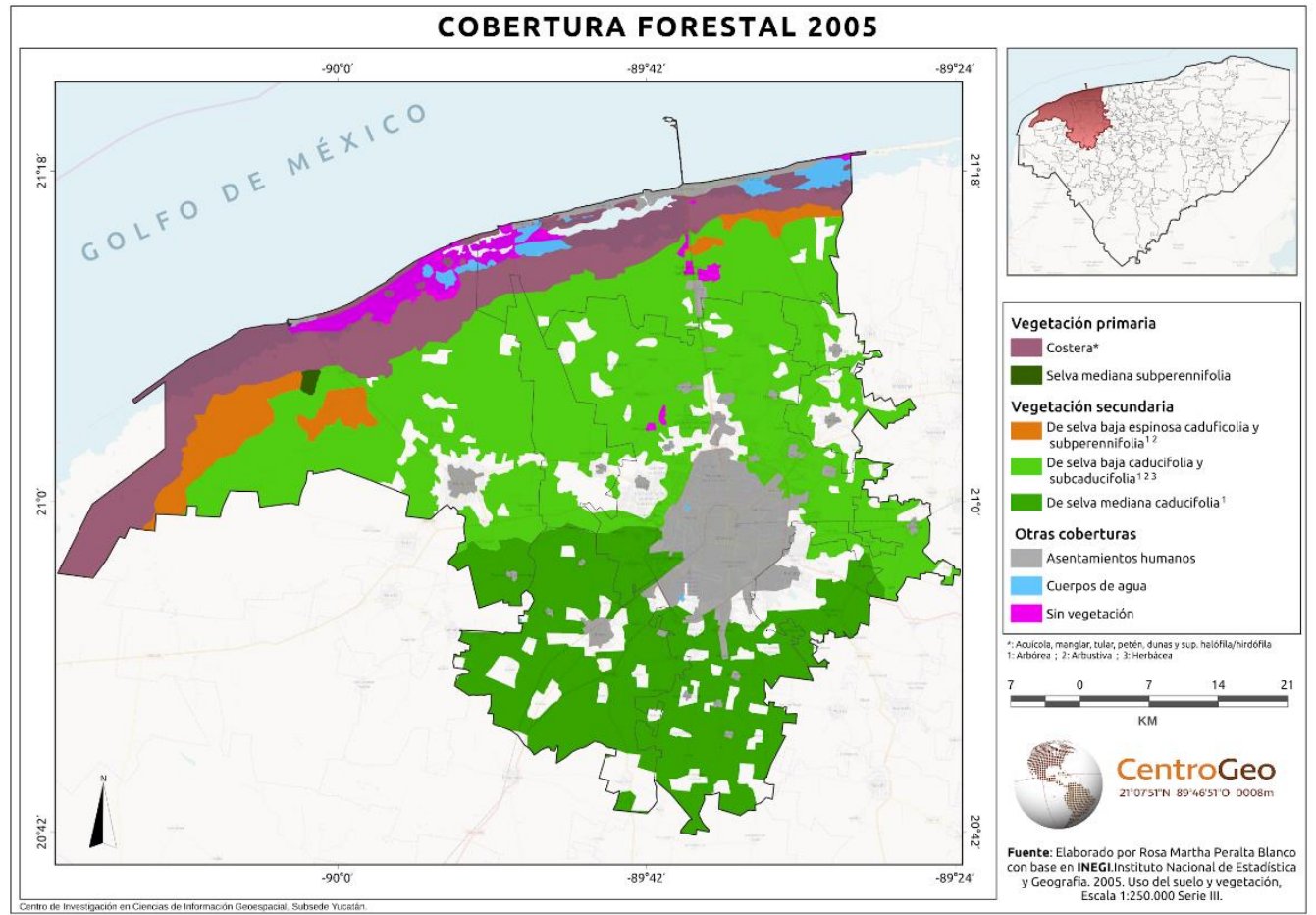

Mapa 2. Cobertura forestal 2015

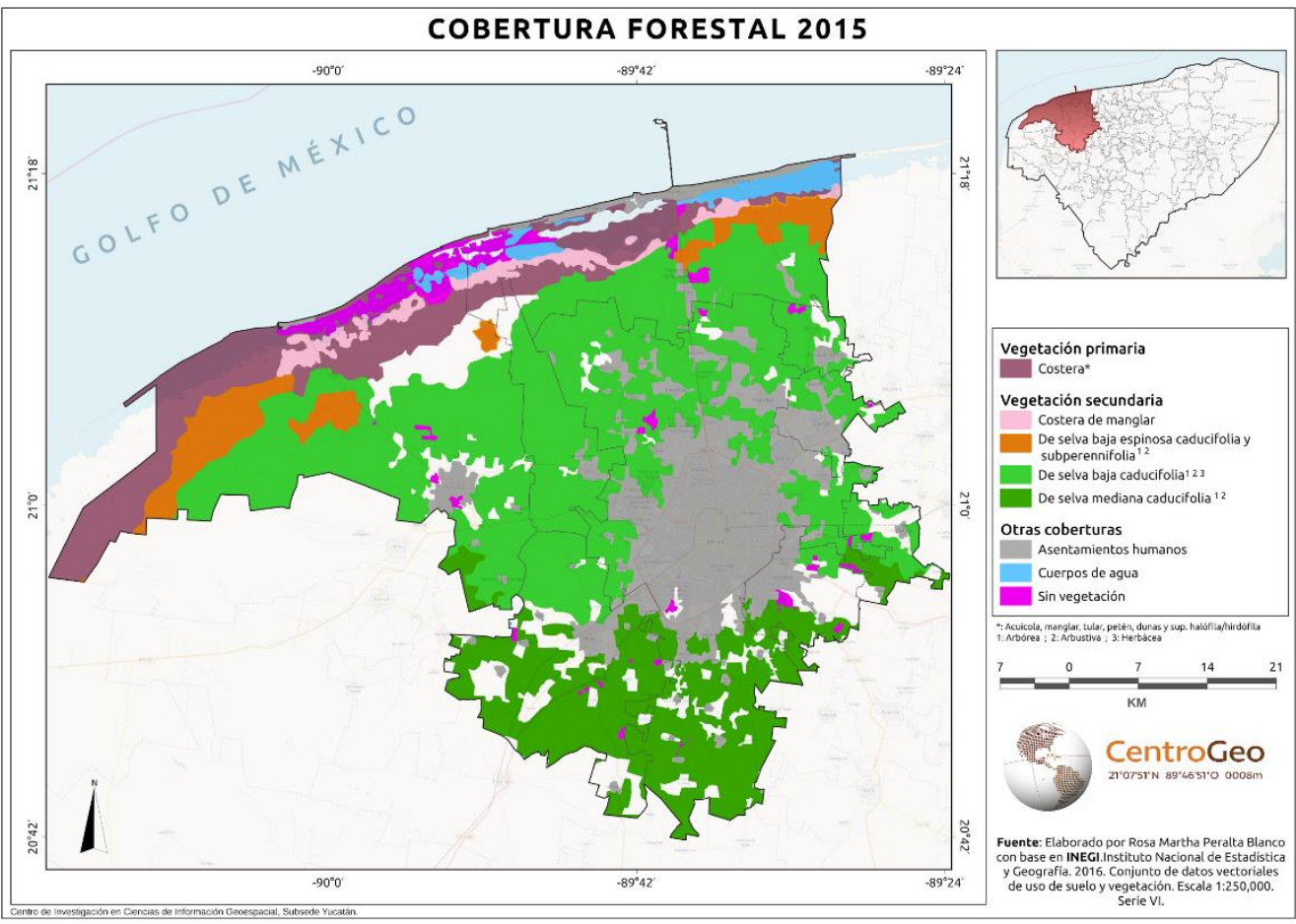


AÑO 22, 2020-1 ENERO-JUNIO E-ISSN 2594-102X PÁGS. 97-126 II:_-

Mapa 3. Cambio en la cobertura forestal 2005-2015

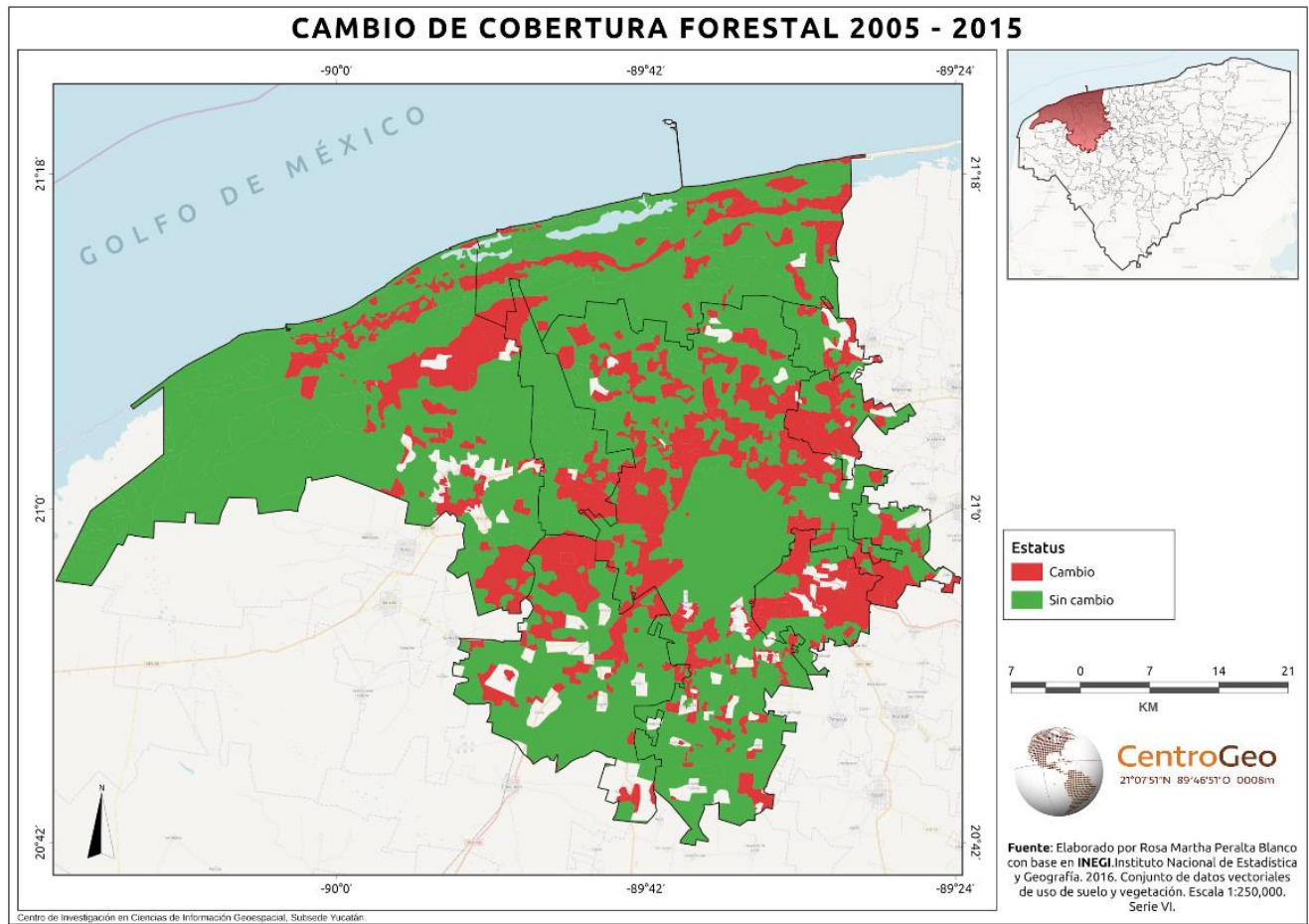

Mapa 4. Áreas naturales protegidas 2005

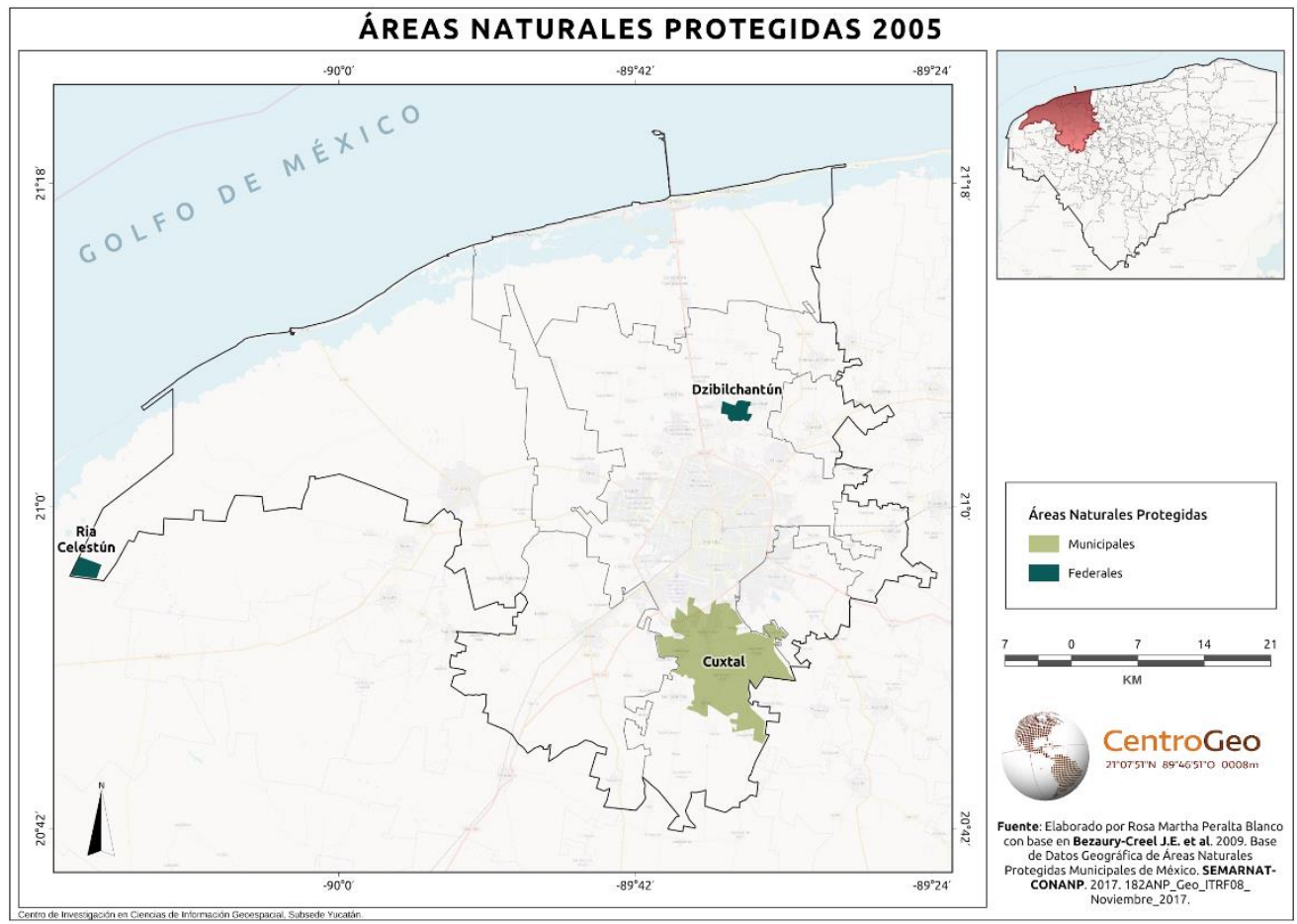


Mapa 5. ANPs y Corredor Biológico Mesoamericano 2015

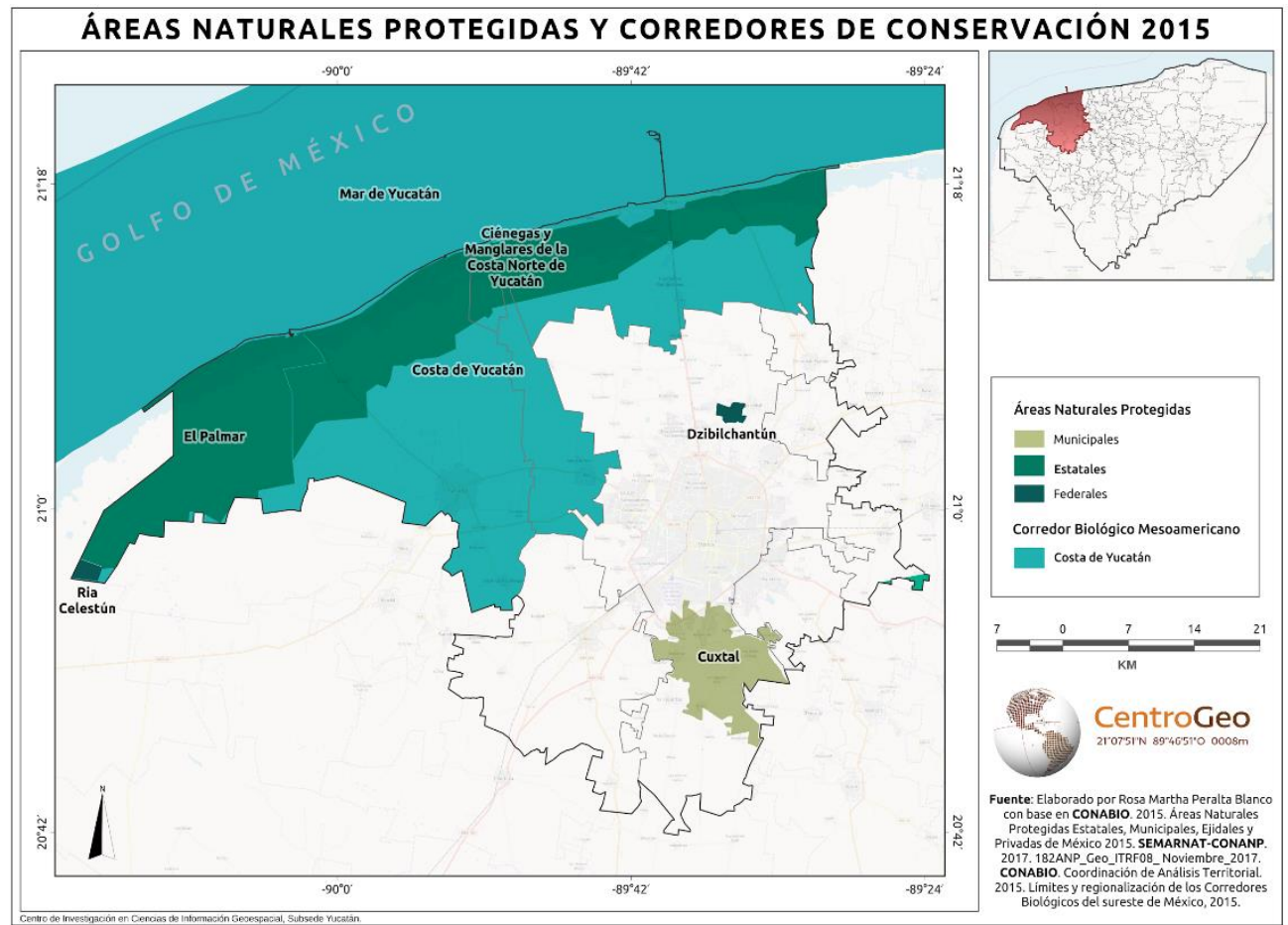

Cartografía de los actores al noroeste de Yucatán

Mapa 6. Actividades agropecuarias 2005

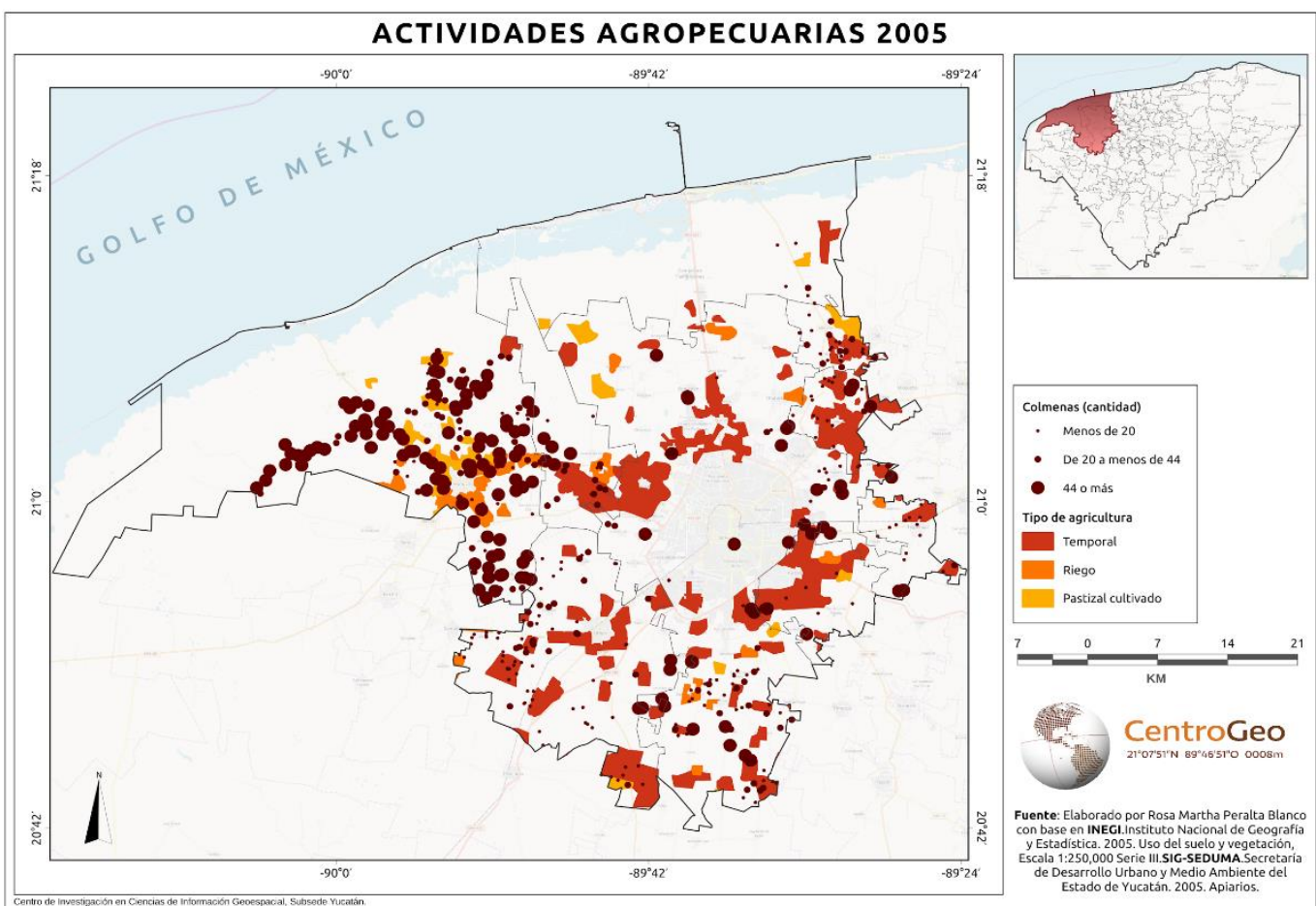




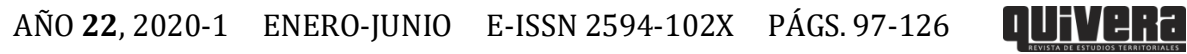

Mapa 7. Actividades agropecuarias 2015

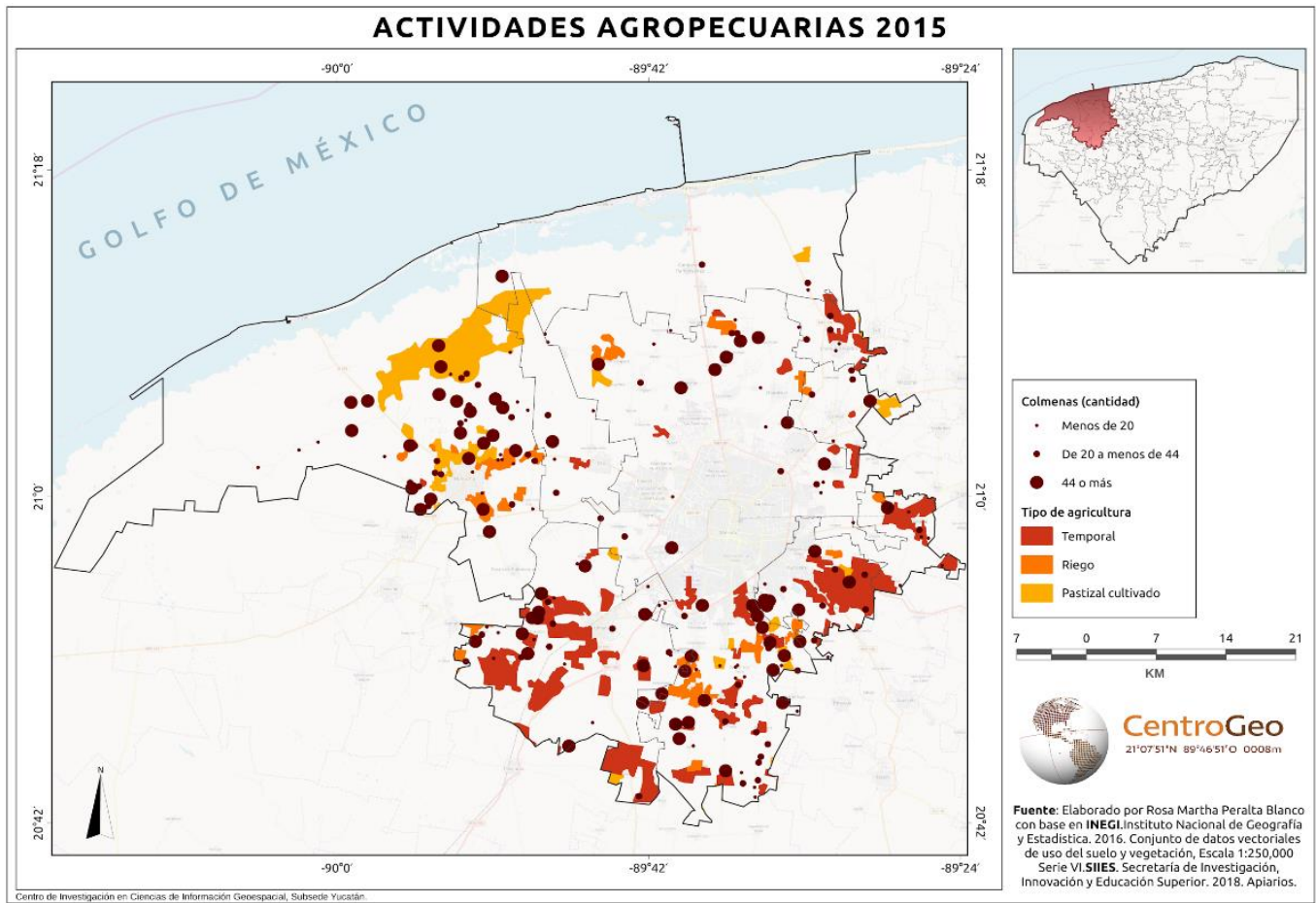

Mapa 8. Cambio en las actividades agropecuarias 2005-2015

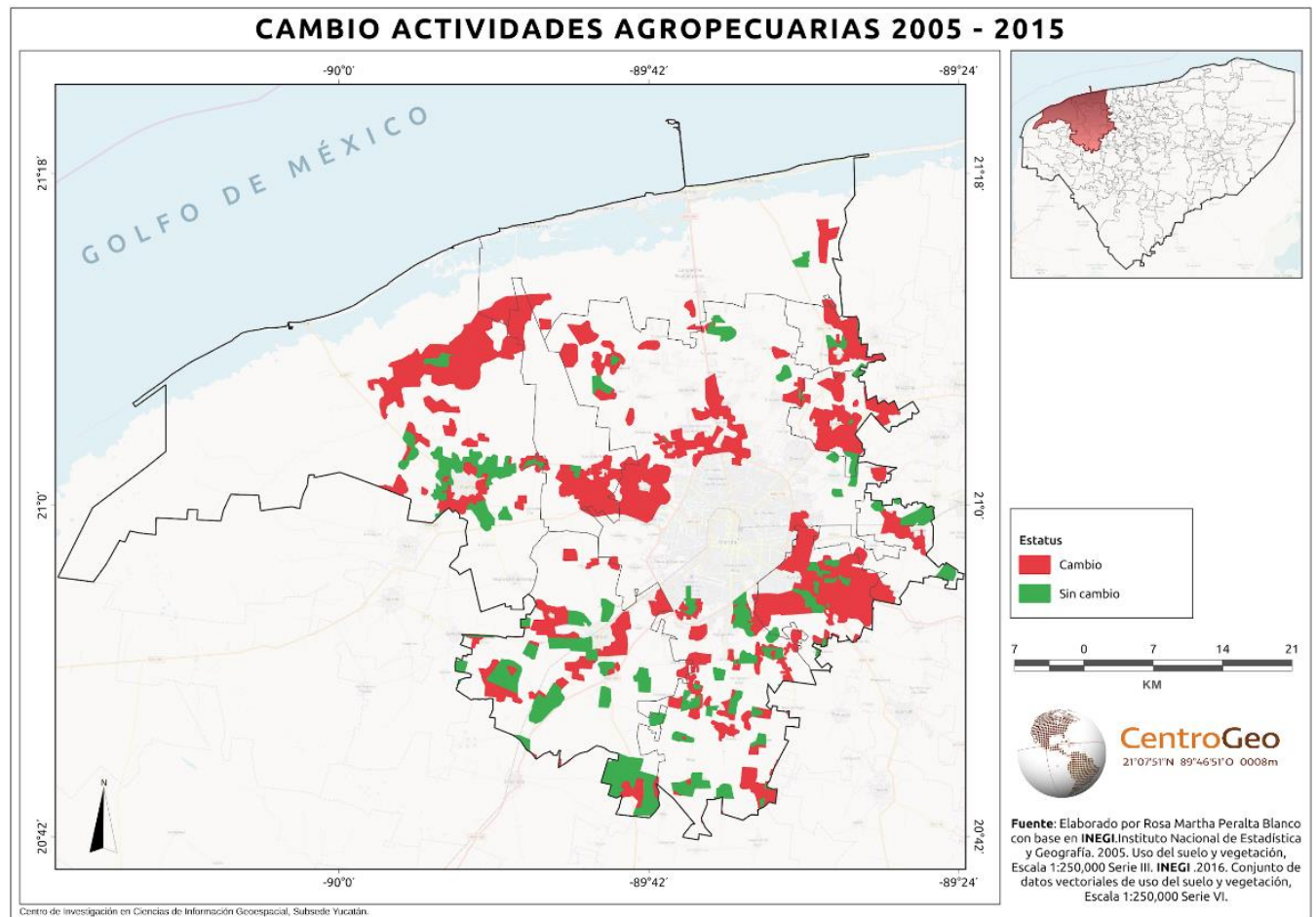


Mapa 9. Unidades económicas pesqueras 2010-2013

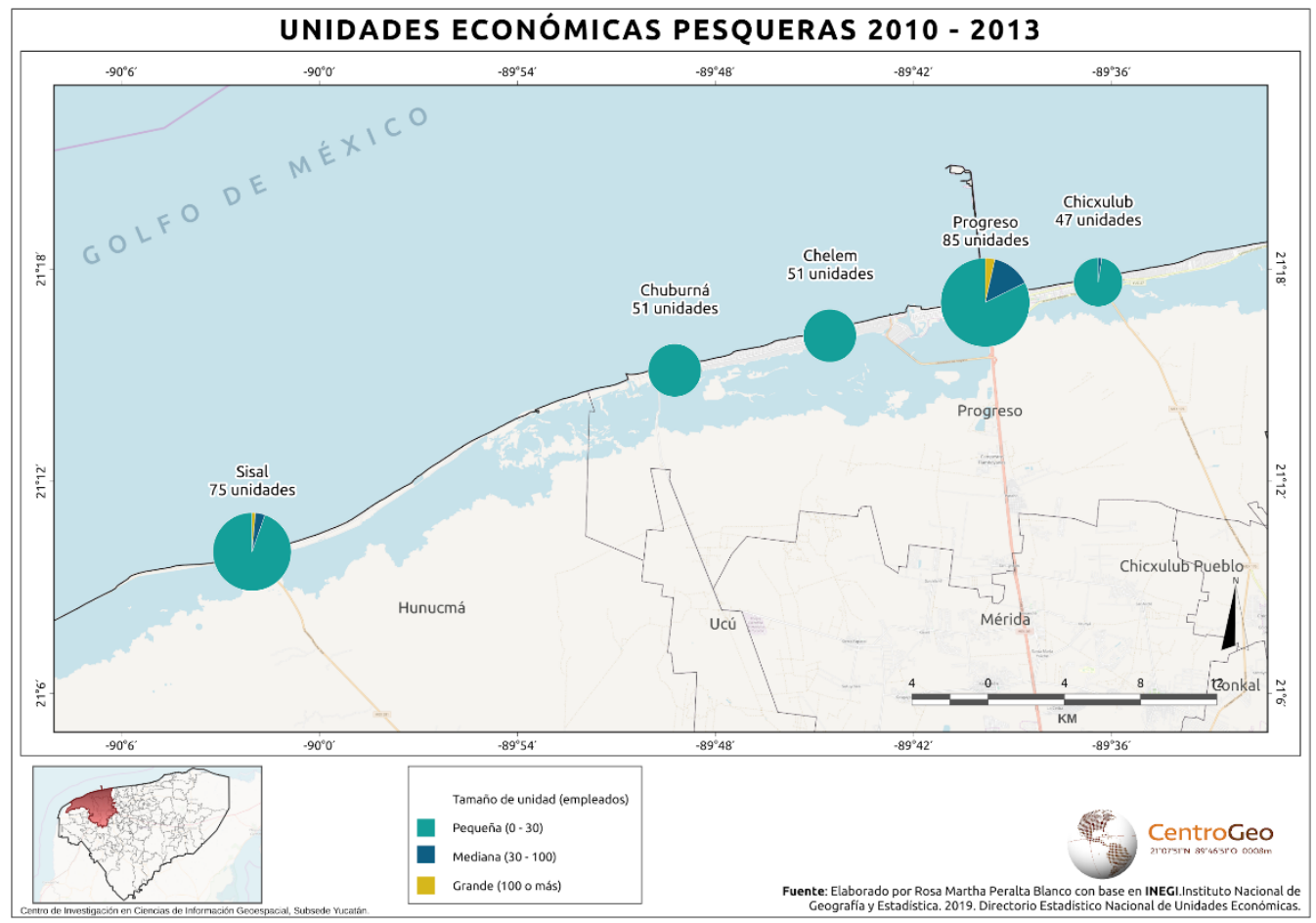

Mapa 10. Sectores económicos 2015 y parques industriales 2019

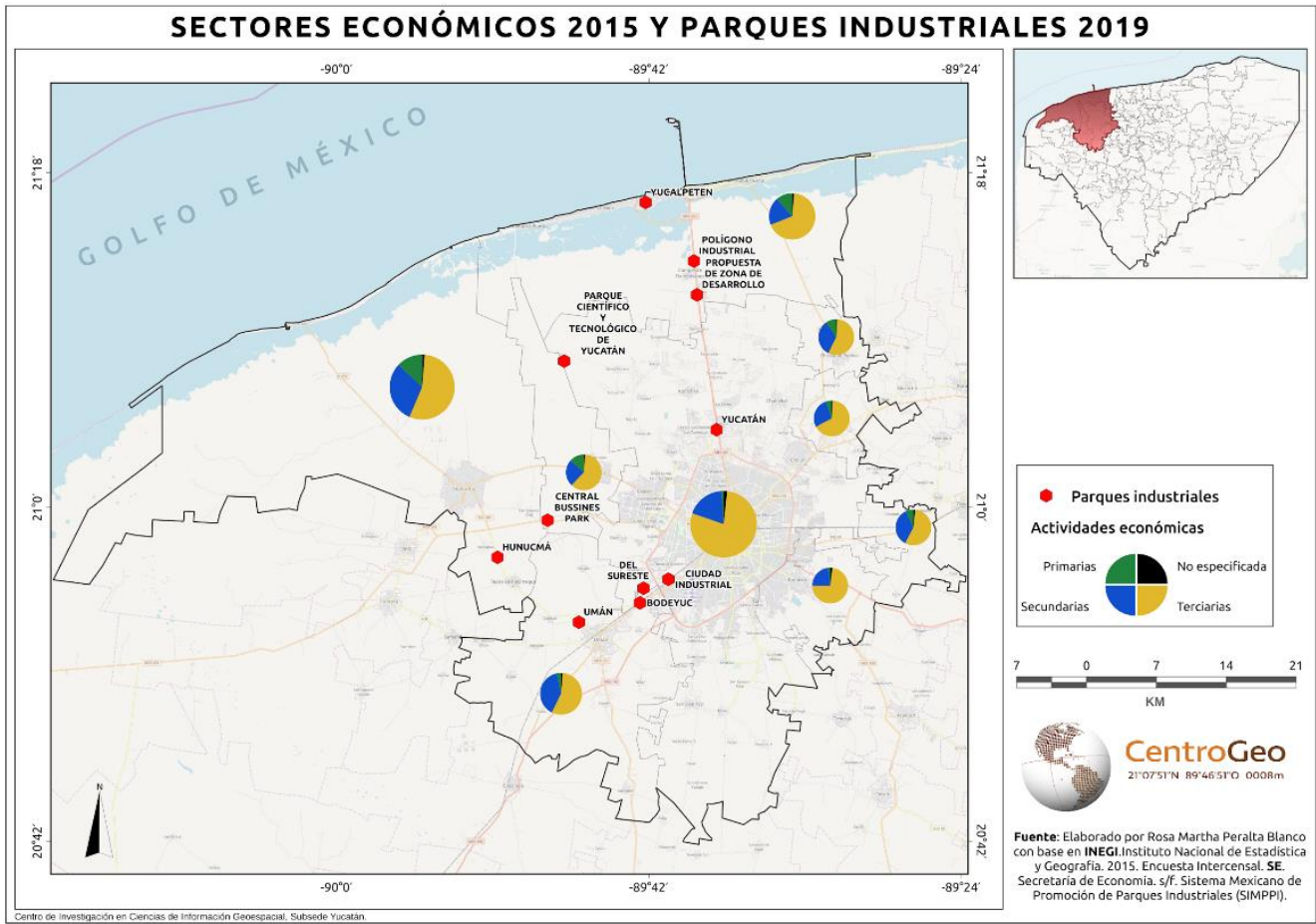


Cartografía de la gobernanza al noroeste de Yucatán

Mapa 11. Tenencia de la tierra 2007

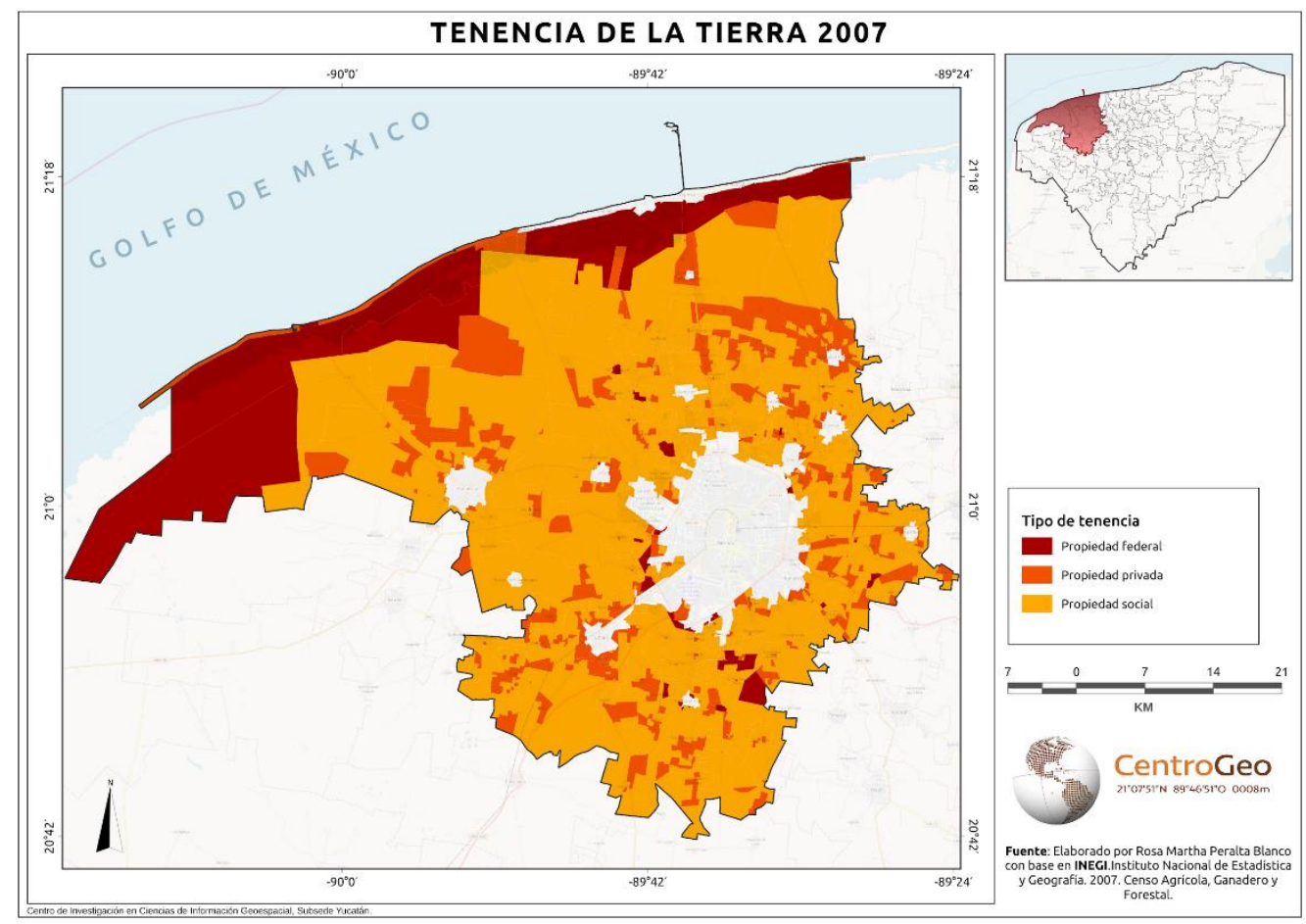

Mapa 12. Densidad poblacional 2005

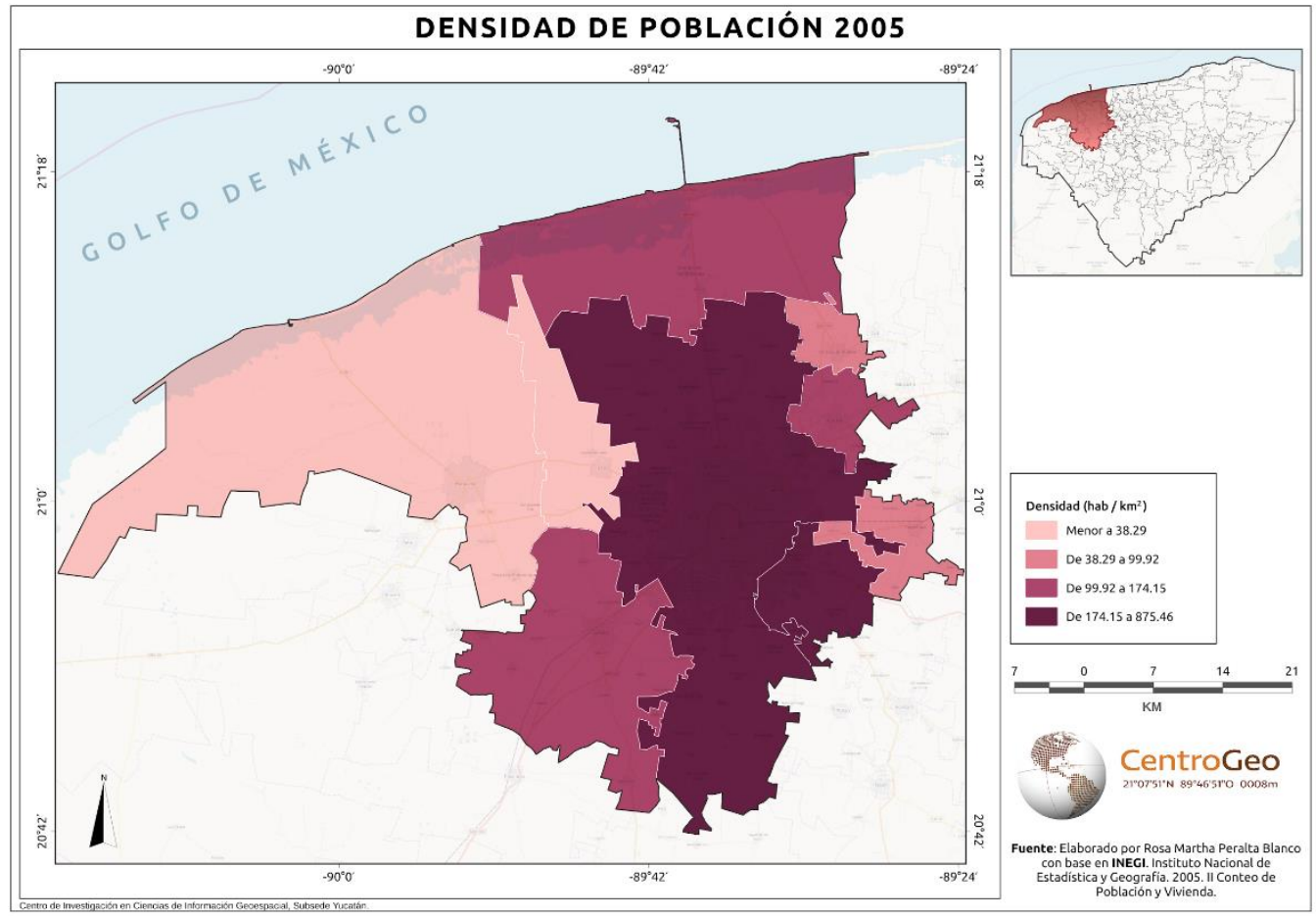


Mapa 13. Densidad poblacional 2015

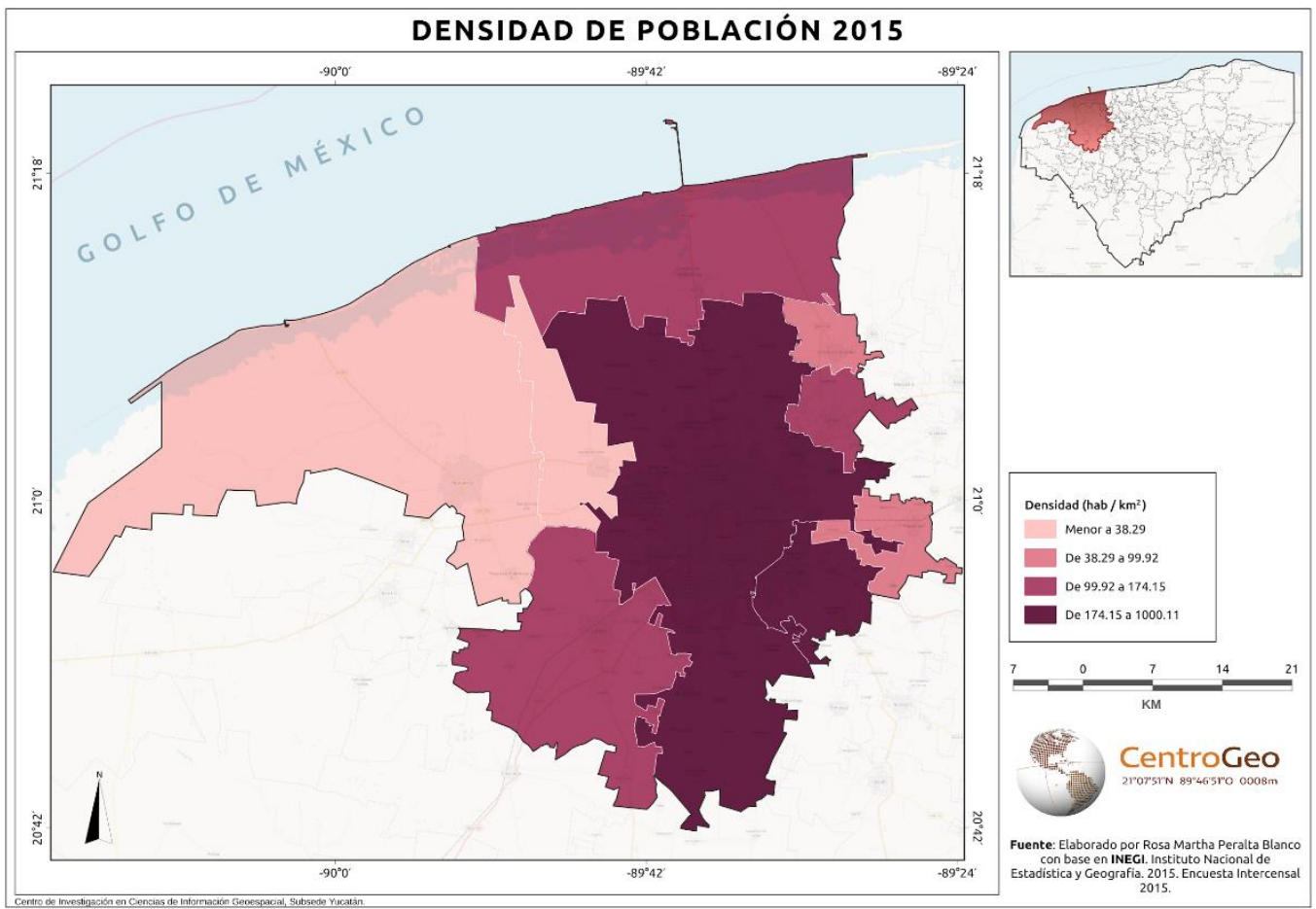

Mapa 14. Porcentaje de población indígena 2015

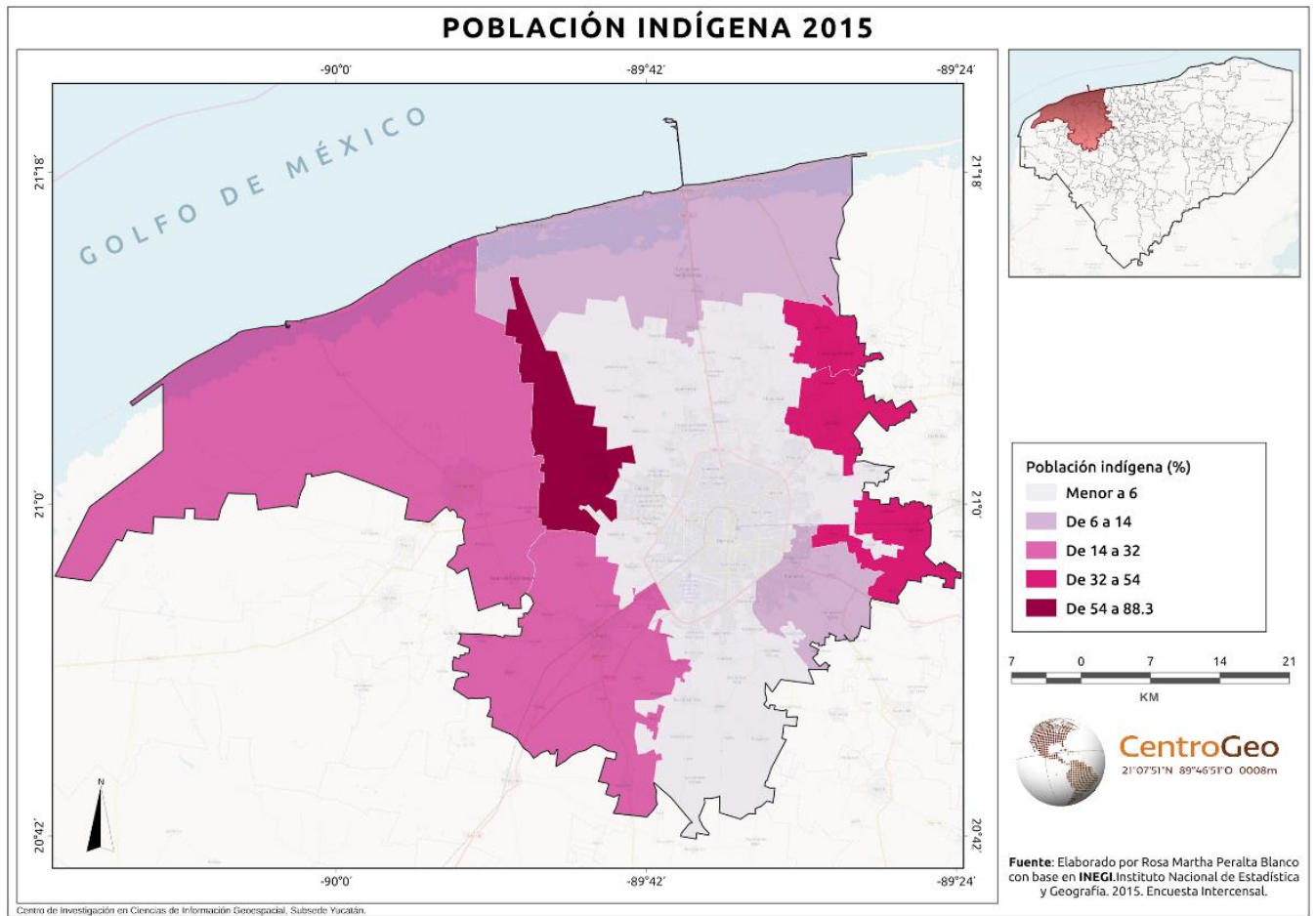


Cartografía transversal a los SSE

Mapa 15. Ganancia de superficie 2005-2015

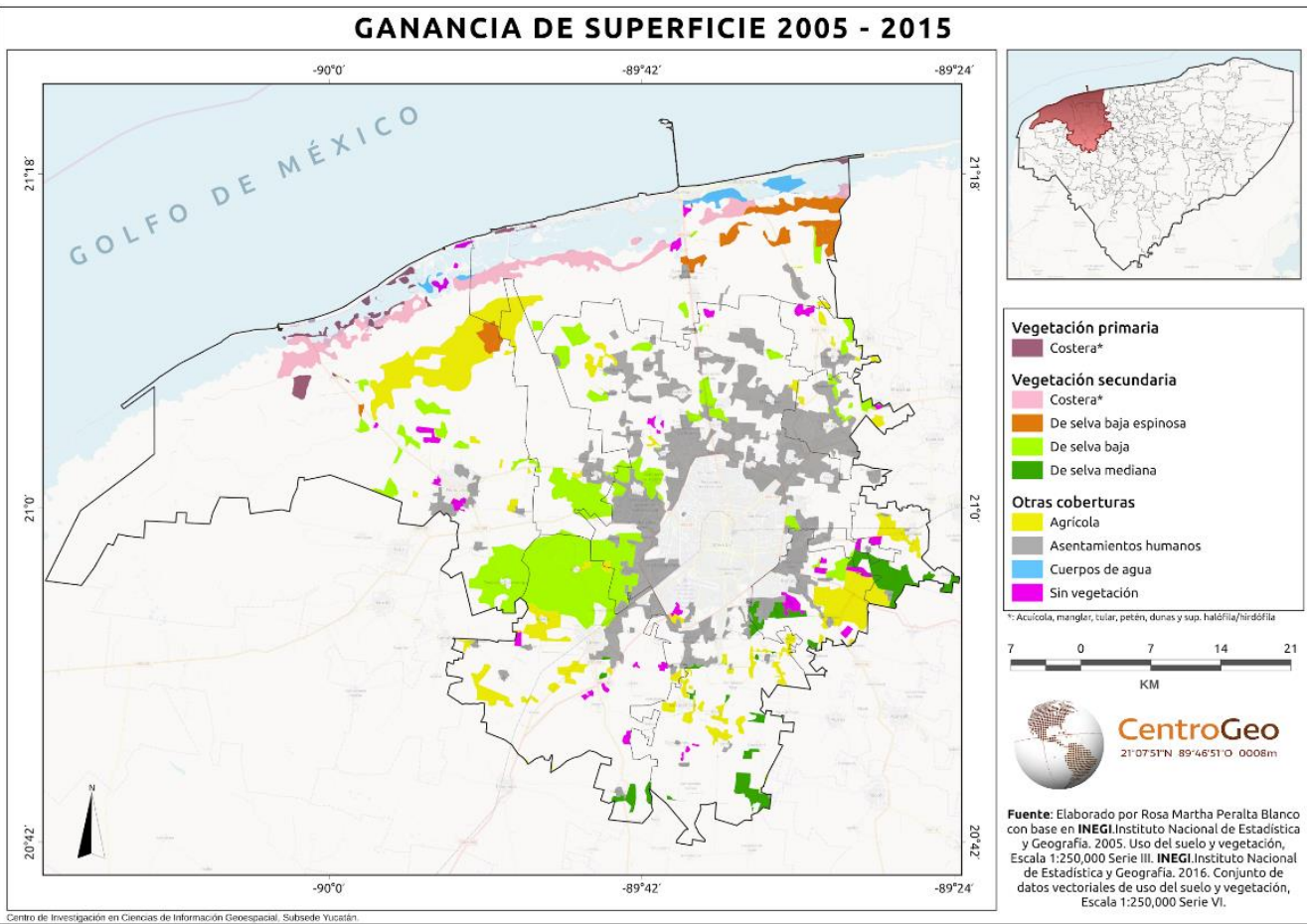

Mapa 16. Pérdida de superficie 2005-2015

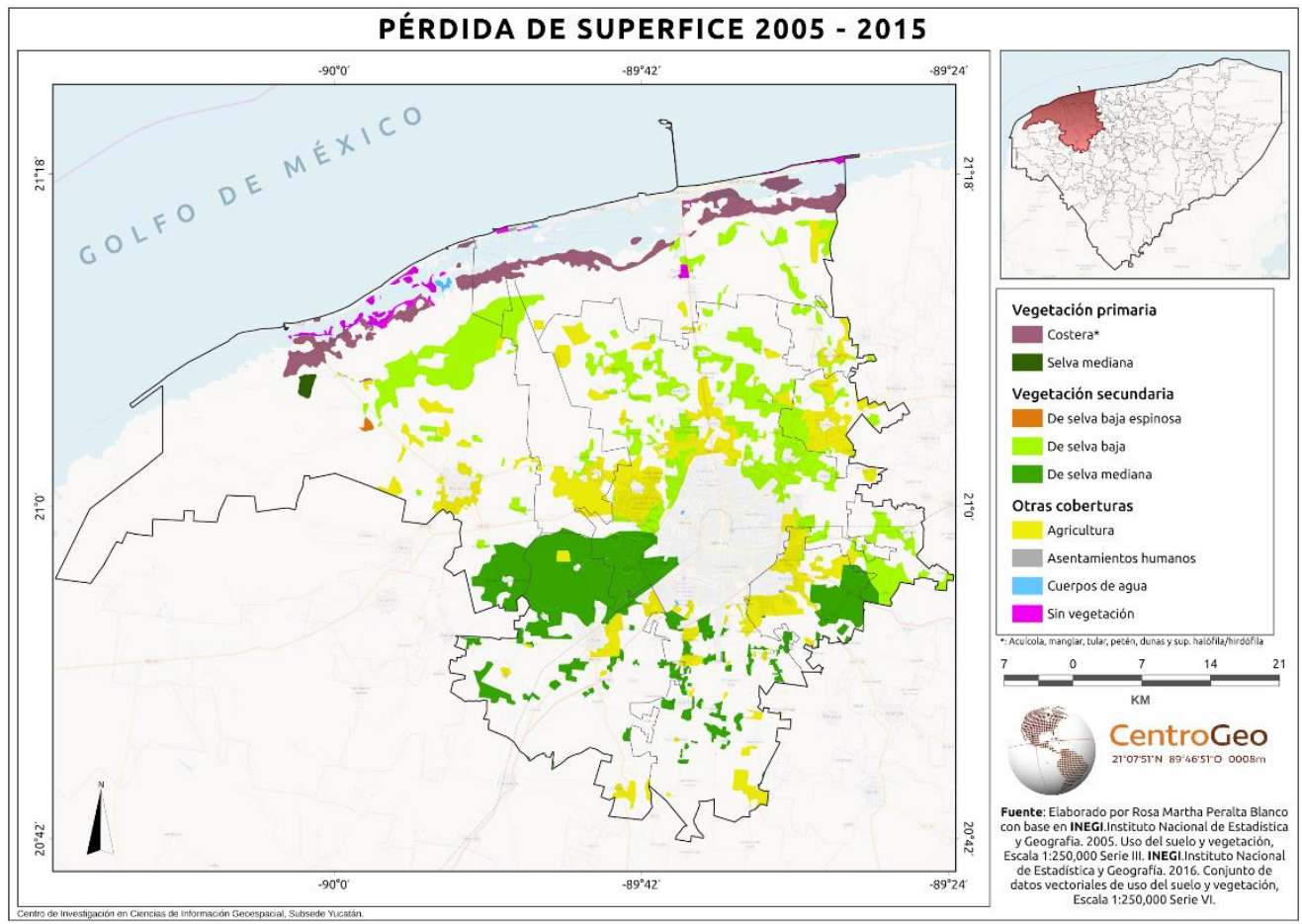


Mapa 17. Crecimiento de la mancha urbana 2005-2015

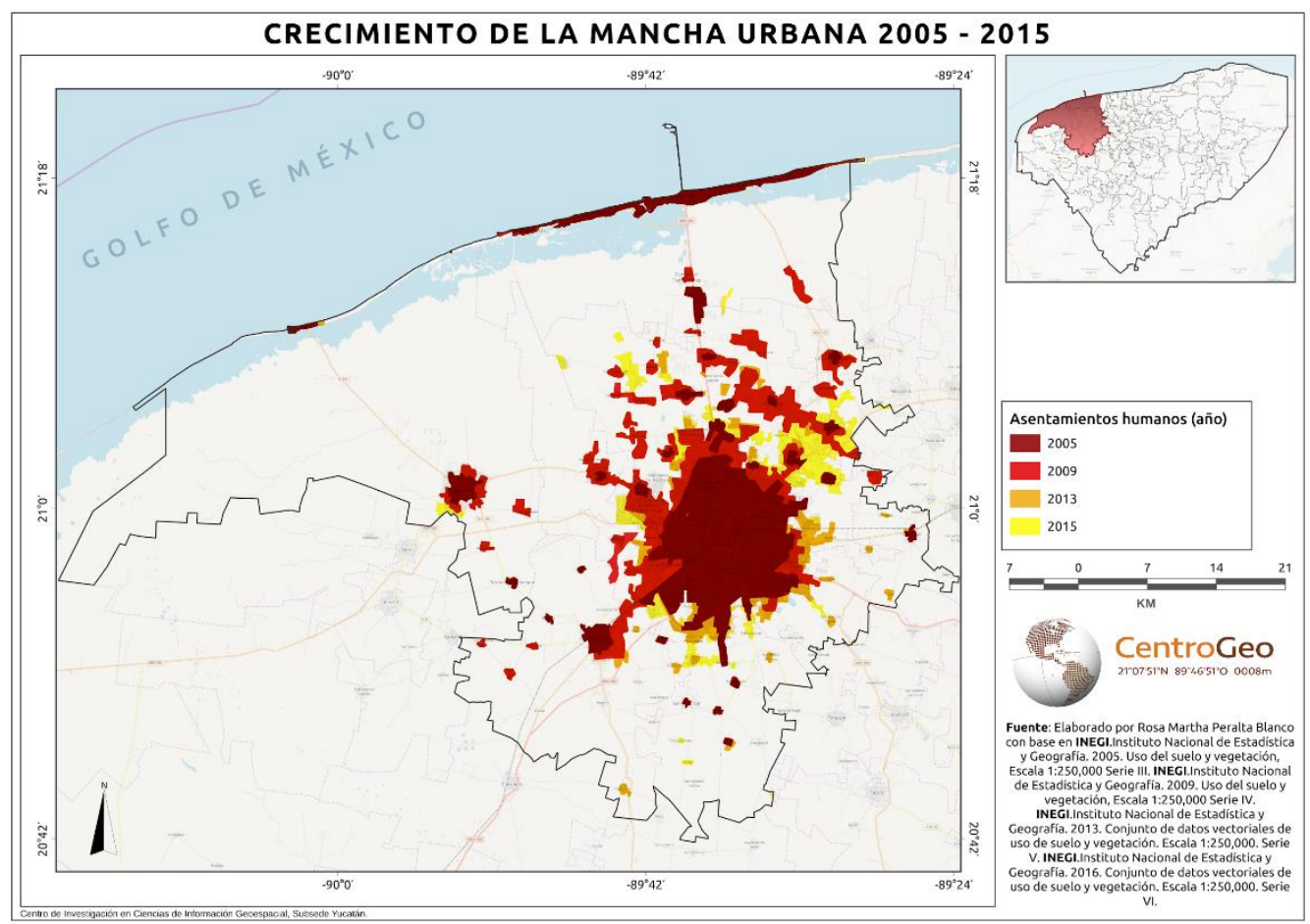

